Research Article

\title{
Dynamic Responses of Planar Multilink Mechanism considering Mixed Clearances
}

\author{
Xiulong Chen $(\mathbb{D}$, Shuai Jiang, and Yu Deng \\ College of Mechanical and Electronic Engineering, Shandong University of Science and Technology, Qingdao 266590, China \\ Correspondence should be addressed to Xiulong Chen; cxldy99@163.com
}

Received 25 November 2019; Revised 21 January 2020; Accepted 21 February 2020; Published 16 March 2020

Academic Editor: Hassan Haddadpour

Copyright (C) 2020 Xiulong Chen et al. This is an open access article distributed under the Creative Commons Attribution License, which permits unrestricted use, distribution, and reproduction in any medium, provided the original work is properly cited.

\begin{abstract}
Translational and revolute joints are the main kinds of joints in planar multilink mechanisms. Translational and revolute clearance joints have great influence on dynamical responses of planar mechanisms. Most research studies mainly focused upon revolute clearance of planar mechanisms based upon the modified Coulomb friction model, some studies investigated clearance of the pinslot joint, and few studies researched mixed clearances (considering both translational clearance and revolute clearance) based on the LuGre friction model. Dynamic response of the 2-DOF nine-bar mechanism considering mixed clearances based on the LuGre model is investigated in this work. The dynamic model with mixed clearances is built by the Lagrange multipliers. Dynamic responses including motion output of the slider, driving torques, contact forces, shaft center trajectories at revolute clearance pairs, and slider trajectory inside the guide are analyzed, respectively. Influences of different friction models on dynamic responses are studied, such as LuGre and modified Coulomb's friction models. Effects of different clearance values and different driving speeds on dynamic responses with mixed clearances are both analyzed. Virtual prototype model considering mixed clearances is carried out through ADAMS to verify correctness.
\end{abstract}

\section{Introduction}

Planar multilink mechanisms are widely applied in engineering, such as mechanical press, agricultural equipment, medical apparatus and instruments, and precision instrument [1-4]. Translational and revolute joints are important parts to connect each component of planar multilink mechanisms. Translational and revolute clearances will cause impact between components, which will lead to a deviation between the expected output and the real output, and it also degrades the accuracy and stability [5-9]. Dynamic characteristics of multilink mechanisms become worse. So, it is important to study the effect of mixed clearances on dynamic responses of planar multilink mechanisms.

In the recent decades, many scholars have studied the dynamic behavior of mechanical systems containing revolute pair clearances. Most of the researches used the modified Coulomb friction model to build friction force at revolute clearance joints [10-22]. Wang et al. [10] put forward a nonpenetration method for the planar rigid slidercrank mechanism considering revolute clearance. Zhang et al. [11] analyzed dynamic responses of the planar parallel mechanism considering six revolute clearance pairs. Varedi et al. [12] put forward an optimization model for a slidercrank mechanism to optimize mass distribution of the linkages to reduce contact forces at revolute clearances. Chen et al. [13] discussed the effect of various factors on dynamical response of the crank-slider mechanism through ADAMS. Chen et al. [14] analyzed the dynamics of a hydraulic rock-breaker mechanism containing revolute clearances. Li-Xin et al. [15] analyzed effects of revolute clearances on the dynamical behavior of a planar 2-DOF parallel manipulator. Hou et al. [16] developed a dynamical equation of the RU-RPR mechanism containing single clearance. Li et al. [17] investigated influence of the harmonic drive on dynamics of the mechanism considering clearances. Erkaya and Doğan [18] constituted a pseudorigid 
body model of compliant crank-slider mechanism containing revolute clearance. Wang et al. [19] analyzed nonlinear dynamics of the flexible crank-slider mechanism considering clearance. Farahan et al. [20, 21] studied nonlinear dynamic behavior of simple mechanism considering revolute clearance by using Poincaré portraits and the bifurcation diagram. Flores et al. [22] discussed the effect of various contact force models on dynamics of a simple mechanism containing single clearance.

Some scholars studied dynamic responses of planar simple mechanisms with revolute clearances by using the LuGre model to build friction, such as slider-crank mechanism. Studies on dynamical responses of planar multilink mechanisms containing multiple revolute clearances by combining the LuGre friction model are few [23-26]. Muvengei et al. [23] analyzed dynamical responses of the crank-slider mechanism with clearances considering stickslip friction. Jiang et al. [24] studied on the wear characteristics of the multilink mechanism with multiple revolute pair clearances. Marques et al. [25] examined and compared 21 different friction force models on dynamics of the crankslider mechanism with clearance. Muvengei et al. [26] have carried out detailed analysis to the movement state of the clearance of two rotation pairs in a crank-slider mechanism.

In the past few years, some research studies were conducted to study the effect of translational clearance and pinslot clearance joint on dynamic responses of mechanical systems, and the existing literatures mainly considered the crank-slider mechanism as the research object. Studies on dynamic responses of planar multilink mechanisms containing mixed clearances by the LuGre model have not been found in the existing literature. Skrinjar et al. [27, 28] discussed the influence of pin-slot clearance joint on kinematic and dynamic characteristics. Flores et al. [29] put forward a methodology for rigid planar mechanism containing translational clearance joints. Several possible motion cases between the slider and guide were both analyzed. Zhuang and Wang [30] presented an approach for analyzing and modeling the rigid multibody mechanism considering translation clearance and driving constraints. Zhang and Wang [31] put forward an FEM for the multibody system containing a translational clearance. Flores et al. [32] presented a method based upon the nonsmooth dynamical approach to build and analyze the dynamic model for the rigid crank-slider mechanism considering translational clearance. Wang et al. [33] analyzed the impact of revolute clearance and translational clearance on dynamics of crankslider mechanism. Zhan et al. [34] proposed the motion reliability analysis methodology of planar parallel manipulators containing revolute and prismatic joint clearances.

Previous studies investigated the effects of translational or revolute clearances on dynamic behavior independently, rather than considering effects of these two kinds of clearances on the dynamics of planar multilink mechanisms simultaneously. Effects of mixed clearances on dynamical responses of planar multilink mechanisms by the LuGre model are rarely investigated, and previous studies mainly use the modified Coulomb friction model as the friction force model. Therefore, this paper studied the dynamical responses of 2-DOF nine-bar mechanism considering mixed clearances based on the LuGre model. Dynamics model containing mixed clearances was developed by Lagrange multipliers. Dynamic response, such as motion output of the slider, driving torques, contact forces, shaft center trajectories at revolute clearance pairs, and slider trajectory inside the guide, is obtained. Influences of the different friction models, clearance values, and driving speeds on dynamic responses with mixed clearances are analyzed. Virtual prototype model containing mixed clearances has been modeled through ADAMS to verify correctness.

\section{Modeling of Translational Clearance}

2.1. Kinematic Model. Translational clearance model is shown in Figure 1. Figures 1(a) and 1(b) are the front view and side view of the slider. Length and width of the slider are $L$ and $W$, total distance between guide surfaces is $H$, and slider thickness is T. $a$ is half of the perimeter of the rectangular contact side surface of the slider, $a=T+L[29,33]$; $c$ is the clearance value, and its expression is written as

$$
c=\frac{H-W}{2} \text {. }
$$

When the slider moves inside the guide, four position cases between the slider and the guide are displayed, as in Figure 2.

The translational clearance model is displayed in Figure 3 [29]. The slider is the component $m$, guide is the part of the component $n, o_{m}$ and $o_{n}$ are the centroids of the slider and the guide, local coordinate systems of the slider and the guide are $x_{m} o_{m} y_{m}$ and $x_{n} o_{n} y_{n}$, respectively, and the global coordinate system is $X O Y$.

Set $\bar{P}, \bar{Q}, \bar{R}$, and $\bar{T}$ as the geometric constraint points on the guide that may make contact with the slider. $\bar{A}_{m}, \bar{B}_{m}, \bar{C}_{m}$, and $\bar{D}_{m}$ the corners of the slider, $\bar{A}_{n}, \bar{B}_{n}, \bar{C}_{n}$, and $\bar{D}_{n}$ are the points on the guide that are close to the slider's corner. Because the location equation of each corner on the slider is similar to each other, only the mathematical model of point $\bar{A}$ is described.

Position vector of any point $H$ on component $k$ in the global coordinate system is

$$
\mathbf{r}_{k}^{H}=\mathbf{r}_{k}+\mathbf{A}_{k} \mathbf{s}_{k}^{H}, \quad k=m, n,
$$

where $\mathbf{r}_{k}$ and $\mathbf{A}_{k}$ are, respectively, the position vector and the transformation matrix of component $k$ and $\mathbf{s}_{k}^{H}$ is the position vector of point $H$.

Vector that connects slider corner $\bar{A}_{m}$ to the point $\bar{A}_{n}$ on the guide surface is

$$
\boldsymbol{\delta}=\mathbf{r}_{n}^{\bar{A}}-\mathbf{r}_{m}^{\bar{A}}
$$

Normal vector $\mathbf{n}$ of the guide surface is

$$
\mathbf{n}=\left[\begin{array}{ll}
t_{y} & -t_{x}
\end{array}\right]^{\mathrm{T}}
$$

where $t_{x}$ and $t_{y}$ are the components of the tangential vector in the direction of $X$ and $Y$.

When the slider and guide are pressed into each other, vector $\boldsymbol{\delta}$ is parallel to normal vector $\mathbf{n}$ of the guide surface, but the direction is opposite. 


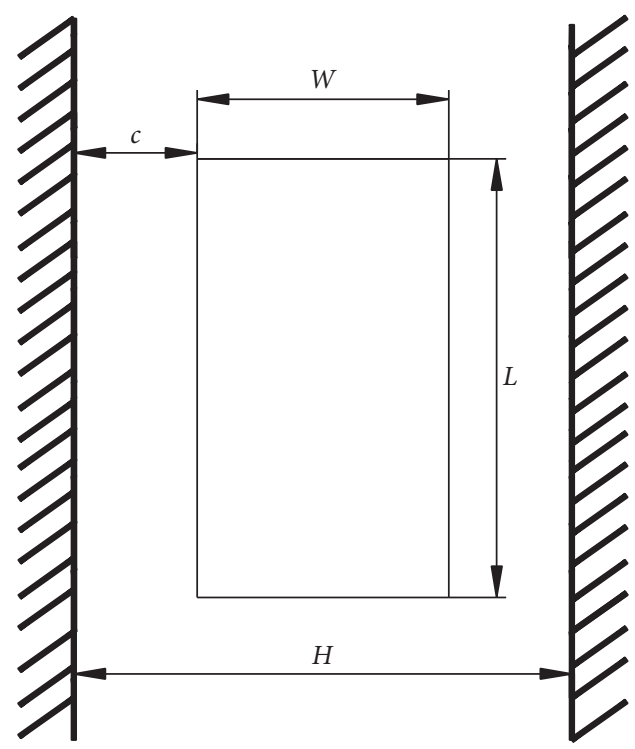

(a)

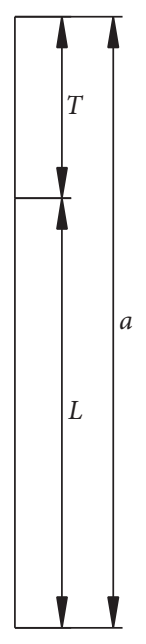

(b)

Figure 1: Translational clearance model. (a) Front view of the slider. (b) Side view of the slider.

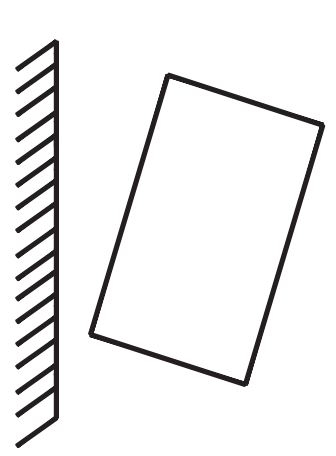

(a)

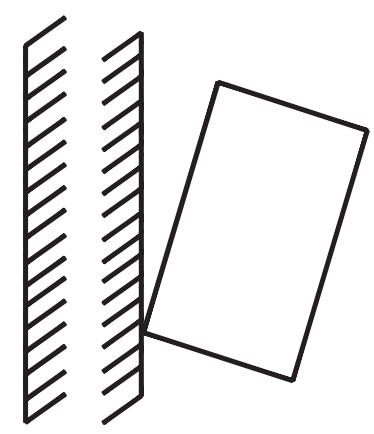

(b)

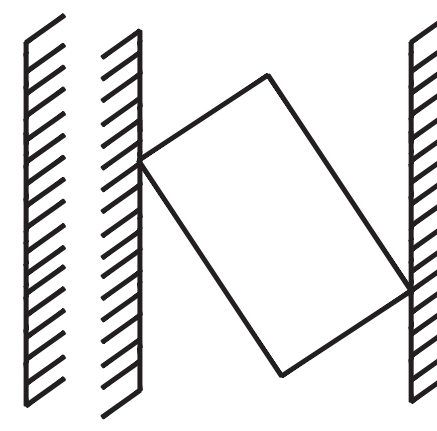

(c)

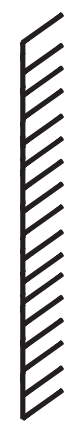

(d)

FIgURE 2: Relative position cases between slider and guide.

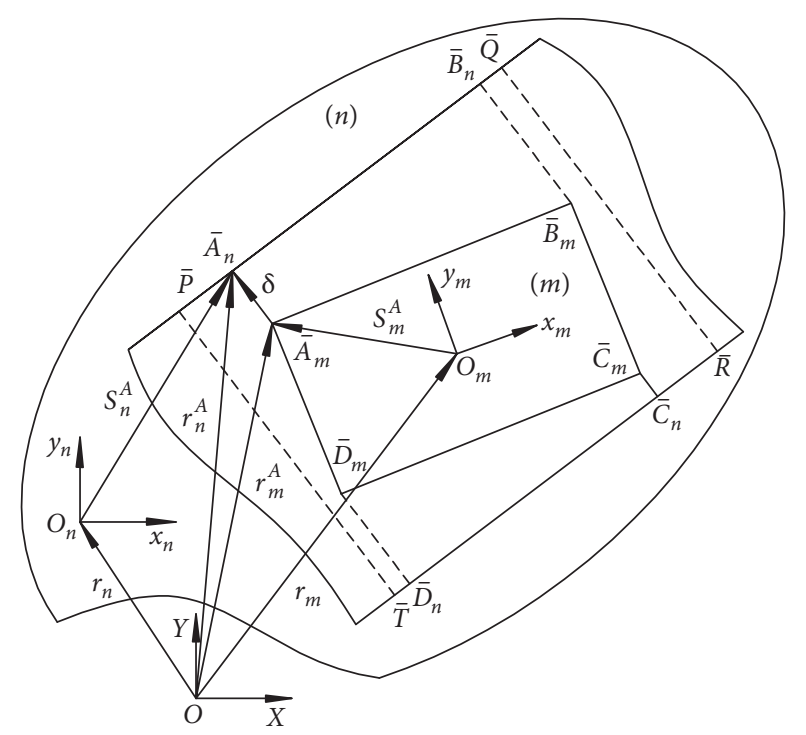

Figure 3: Analysis model of the translational clearance model.
Therefore, the penetration condition for the contact is

$$
\mathbf{n}^{\mathrm{T}} \boldsymbol{\delta}<0 .
$$

Magnitude of penetration depth can be given by

$$
\delta=\sqrt{\boldsymbol{\delta}^{\mathrm{T}} \boldsymbol{\delta}} \text {. }
$$

\subsection{Force Model of Translational Clearance}

2.2.1. Normal Force Model. While two adjacent slider corners contact with the guide, collision force acts on the centroid of the embedded region, marked as $G$ in Figure 4(a). Contact force could be expressed as $[5,29]$

$$
F_{n}=K \delta
$$

where stiffness parameter $K$ could be written as [29].

$$
K=\frac{a}{0.475\left(\sigma_{m}+\sigma_{n}\right)},
$$




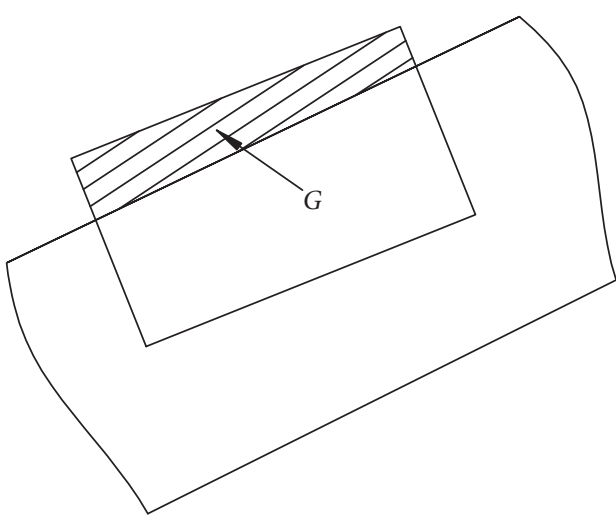

(a)

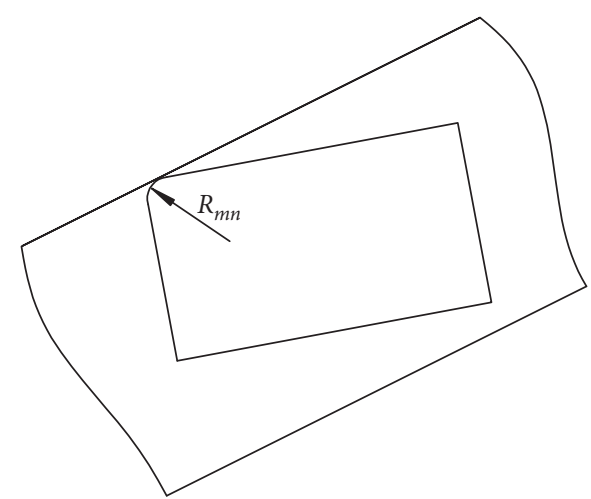

(b)

Figure 4: Contact mode between slider and guide. (a) Contact between two plane surfaces. (b) Contact between a plane and a spherical surface.

where $a$ is half of the perimeter of the rectangular contact surface of the slider, $\sigma_{l}=\left(1-v_{l}^{2} / E_{l}\right)(l=m, n), E_{l}$ is the elastic modulus, and $v_{l}$ is Poisson's ratio.

As shown in Figure 4(b), when one or two opposite slider corners contact with the guide surface, it is assumed that the contact is between a spherical surface and a plane, and the contact force model can be given by

$$
F_{n}=K \delta^{n}+D \dot{\delta}
$$

where $K$ is the generalized stiffness parameter, $K=\left(4 / 3\left(\sigma_{m}+\sigma_{n}\right)\right) \sqrt{R_{m n}}$, and $R_{m n}$ is a small curvature radius, assumed on the contact corner $[5,29]$. The power exponent $n$ depends on material and geometric properties of the contact area [20]. $D$ is the damping coefficient, and it has high accuracy for describing the contact process of clearance elements $[35,36]$, and its expression is defined by

$$
D=\frac{3 K\left(1-c_{e}^{2}\right) \delta^{n}}{4 \dot{\delta}^{(-)}}
$$

where $c_{e}$ means the coefficient of restitution and $\dot{\delta}^{(-)}$is the initial contact velocity.

2.2.2. Tangential Force Model. Superimposing Coulomb, viscous, stiction, and Stribeck models, we could get a complete static friction model that could be used to build stick-slip motions. However, discontinuity of force at zero speed for static friction models poses some numerical challenges and does not model real friction phenomenon. Therefore, some dynamic friction models were researched, such as Dahl friction model and Karnopp friction model. But, in these dynamic friction models, normal force was not considered to result from contact-impact forces arising from influence of clearance and friction models are strongly coupled with the rest of the equations of motion of the system $[23,37]$. LuGre law was proposed by the Canudas de Wit et al. The LuGre model uses the microscopic average bristle deflection of the contacting surfaces as the internal state. In this model, friction is visualized as forces produced by bending bristles. The LuGre model could capture variation of friction force with slip velocity, thus making it suitable for studies involving stick-slip motions. Besides, the LuGre method could be observed to capture the Stribeck effect, which is a phenomenon related to the stick-slip friction $[25,38]$. However, it is very difficult to determine the parameters, and it needs to take a smaller step to solve, so the calculation efficiency is low. Based on classical definition of friction, friction force can be written as [26]

$$
F_{t}=\widetilde{\mu} F_{n} .
$$

Instantaneous coefficient of friction $\mu$ could be given by $[4,23]$

$$
\widetilde{\mu}=\widetilde{\xi}_{0} \widetilde{z}+\widetilde{\xi}_{1} \dot{\tilde{z}}+\widetilde{\xi}_{2} \widetilde{v}
$$

where $\widetilde{\xi}_{0} \widetilde{\xi}_{1}, \widetilde{\xi}_{2}$, and $\widetilde{v}$ are, respectively, the bristle stiffness, microscopic damping coefficient, viscous friction coefficient, and tangential velocity.

Evolution differential equation for average bristle deflection $[4,6,23]$ is written as

$$
\widetilde{\dot{z}}=\widetilde{v}-\frac{\widetilde{\xi}_{0}|\widetilde{v}|}{\widetilde{\mu}_{k}+\left(\widetilde{\mu}_{s}-\tilde{\mu}_{k}\right) e^{-\left(\left|\tilde{v} / \tilde{v}_{s}\right|\right) \tilde{\gamma}}} \widetilde{z},
$$

where $\widetilde{\mu}_{k}, \widetilde{\mu}_{s}, \widetilde{\gamma}$, and $\widetilde{v}_{s}$ are, respectively, kinetic friction coefficient, static friction coefficient, gradient of friction decay, and Stribeck velocity.

Substituting equation (13) into equation (12), we can get

$$
\widetilde{\mu}=\widetilde{\xi}_{0} \tilde{z}\left(1-\frac{\widetilde{\xi}_{0}|\widetilde{v}|}{\widetilde{\mu}_{k}+\left(\widetilde{\mu}_{s}-\widetilde{\mu}_{k}\right) e^{-\left(\left|\tilde{v} / \tilde{v}_{s}\right|\right) \tilde{\gamma}}}\right)+\left(\widetilde{\xi}_{1}+\widetilde{\xi}_{2}\right) \widetilde{v} .
$$

Choice of $\widetilde{z}$ is based on following assumptions [4].

Because simulations at steady-state condition are needed, $\widetilde{z}$ was supposed to be constant for a particular value of relative tangential speed of the members. Therefore, in the steady state, the first derivative of $\widetilde{z}$ is equal to zero, that is, equation $(13)=0$, and $\widetilde{z}$ can be obtained at steady state as follows $[4,23]$ : 


$$
\begin{aligned}
& \dot{\tilde{z}}=\widetilde{v}-\frac{\widetilde{\xi}_{0}|\widetilde{v}|}{\widetilde{\mu}_{k}+\left(\widetilde{\mu}_{s}-\widetilde{\mu}_{k}\right) e^{-\left(\left|\tilde{v} \widetilde{v}_{s}\right|\right) \tilde{\gamma}}} \widetilde{z}=0, \\
& \widetilde{z}=\frac{\widetilde{v}}{|\widetilde{v}|} \cdot \frac{\widetilde{\mu}_{k}+\left(\widetilde{\mu}_{s}-\widetilde{\mu}_{k}\right) e^{-\left(\left|\tilde{v} \widetilde{v}_{s}\right|\right) \tilde{\gamma}}}{\widetilde{\xi}_{0}} .
\end{aligned}
$$

2.2.3. Force Analysis of Translational Clearance. Force and moment acting on the slider $m$ are

$$
\begin{aligned}
F_{m n} & =F_{n} \mathbf{n}+F_{t} \mathbf{t}=\left[\begin{array}{ll}
F_{m n}^{x} & F_{m n}^{y}
\end{array}\right]^{\mathrm{T}}, \\
M_{m n} & =-\left(y_{m}^{Q}-y_{m}\right) F_{m n}^{x}+\left(x_{m}^{Q}-x_{m}\right) F_{m n}^{y} .
\end{aligned}
$$

Force and moment acting on the guide $n$ are

$$
\begin{aligned}
F_{n m} & =-F_{m n}, \\
M_{n m} & =-\left(y_{n}^{Q}-y_{n}\right) F_{n m}^{x}+\left(x_{n}^{Q}-x_{n}\right) F_{n m}^{y} .
\end{aligned}
$$

\section{Modeling of Revolute Clearance}

3.1. Kinematic Model. Revolute clearance model is displayed in Figure 5. Component $i$ and component $j$ are the bearing and the shaft.

Eccentricity vector could be given by

$$
\mathbf{e}=\mathbf{r}_{j}^{P}-\mathbf{r}_{i}^{P}
$$

Penetration depth could be given by

$$
\bar{\delta}=e-\bar{c}
$$

where $\bar{c}$ is the clearance size, $\bar{c}=R_{i}-R_{j}$, in which $R_{i}$ and $R_{j}$ are the radii of the bearing and the shaft.

Criteria for judging whether collision occurs between elements of revolute pair with clearance are as follows $[15,39]: \begin{cases}\bar{\delta}<0, & \text { free flight mode, } \\ \bar{\delta}=0, & \text { continuous contact mode } \\ \bar{\delta}>0, & \text { impact mode. }\end{cases}$

\subsection{Force Model of Revolute Clearance}

3.2.1. Normal Force Model. L-N model is more suitable for general mechanical impact with a high coefficient of restitution, and it is also in well conformity with experimental results. It not only involves energy loss in impact process, but also considers material properties, local elastic deformation, and collision velocity of the collision body; the L-N contact force model is applied $[18,36,40-42]$, and it could be expressed by equation (9), where $K$ is the stiffness parameter, $\quad K=\left(4 /\left(3 \pi\left(\sigma_{i}+\sigma_{j}\right)\right)\right)\left(\left(R_{i} R_{j} /\left(R_{i}+R_{j}\right)\right)\right)^{1 / 2}, \quad \sigma_{k}=$ $\left(\left(1-v_{k}^{2}\right) / E_{k}\right)(k=i, j), v_{k}$ is Poisson's ratio, $E_{k}$ is the elastic modulus, and $D$ is the damping coefficient, which can also be expressed by equation (10).

3.2.2. Tangential Force Model. Friction force might well appear in the revolute clearance joints in the multibody system. The LuGre model is also used in revolute clearance joints to study clearance influence on dynamic response. The

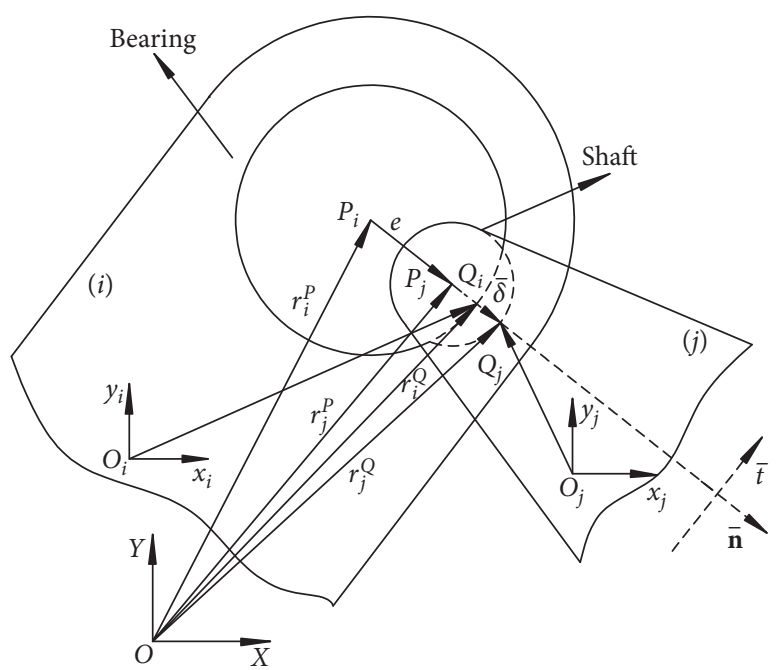

Figure 5: Revolute clearance model.

friction force acting on the revolute clearance can also be expressed by equations (11)-(15).

3.2.3. Force Analysis of Revolute Clearance. Force and moment acting on the bearing and the shaft can be written by equations (16)-(19).

\section{Establishment of Dynamics Model of 2-DOF Nine-Bar Mechanism with Mixed Clearances}

The 2-DOF nine-bar mechanism is assembled of frame, cranks 1 and 4, links 2, 3, 6, and 8, triangular member 7, and slider 9. Link 5 is frame [43]. Crank 1 and link 2 are linked by a revolute clearance pair A. Crank 4 and link 3 are linked by a revolute clearance pair $\mathrm{B}$. Translational clearance is directly related with the slider, which is denoted by $\mathrm{C}$. Therefore, clearances at $\mathrm{A}, \mathrm{B}$, and $\mathrm{C}$ can better reflect impact of clearances on dynamic response. Two cranks are driven by motors. Geometry of 2-DOF nine-bar mechanism with mixed clearances is illustrated in Figure 6.

Because the nine-bar mechanism has good quick return characteristics and the speed of the slider at the bottom dead center is low and stable, the nine-bar mechanism is applied to the multilink mechanical press as the executive mechanism. It can greatly improve the quality of components, ensure the production efficiency of workpiece processing, reduce the vibration and noise in production and improve the service life of mechanisms and moulds, and so on.

Global generalized coordinates of each member are defined as

$$
\mathbf{q}_{i}=\left(\begin{array}{lll}
x_{i} & y_{i} & \theta_{i}
\end{array}\right)^{\mathrm{T}}, \quad i=1, \ldots, 9, i \neq 5,
$$

where $\theta_{i}$ is the angle of component $i$ and $x_{i}$ and $y_{i}$ are the coordinates of the centroid of component $i$ in $X$ and $Y$ direction.

Through the establishment of the kinematic model of the 2-DOF nine-bar mechanism, the expressions of the rotation angle and the coordinates of the centroid in the $X$ and $Y$ directions of each component are obtained. The initial values of generalized coordinates can be obtained by bringing $t=0$ 


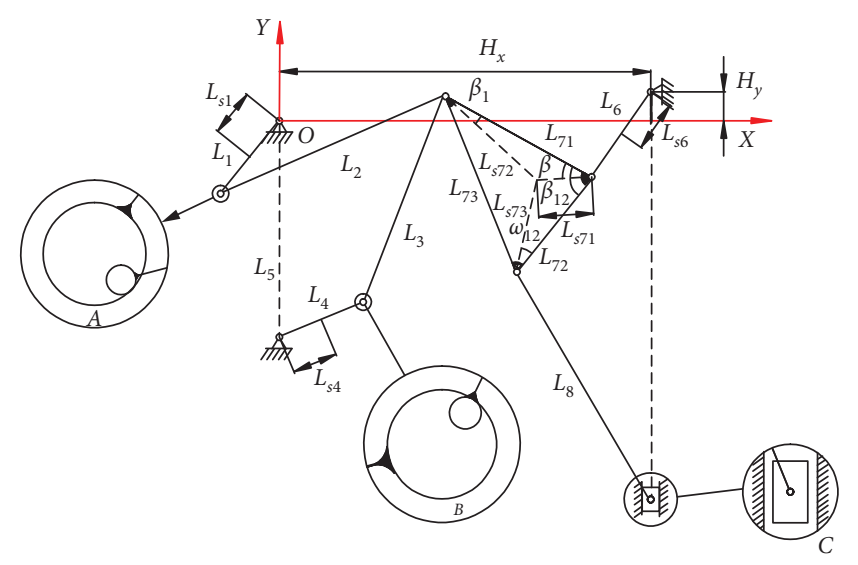

FIGURE 6: Geometry of 2-DOF nine-bar mechanism considering mixed clearances.

into the kinematic model, and initial values of generalized coordinates are defined as

$$
\mathbf{q}_{0}=\left(\begin{array}{c}
0.0200,-0.0114,5.7645,0.1797,-0.1047,5.7530 \\
0.1225,-0.3370,0.6489,-0.0381,-0.4589,-2.4934 \\
0.6440,-0.0351,4.7039,0.5313,-0.2460,-3.0273 \\
0.6436,-0.5676,4.7210,0.6450,-0.7350,4.7123
\end{array}\right)^{\mathrm{T}}
$$

Velocity of global generalized coordinates can be given by

$$
\dot{q}_{i}=\left(\begin{array}{lll}
\dot{x}_{i} & \dot{y}_{i} & \dot{\theta}_{i}
\end{array}\right)^{\mathrm{T}}
$$

When $t=0$, the initial values of velocity of generalized coordinates are defined as

$$
\dot{q}_{0}=\left(\begin{array}{c}
0,0, \omega_{1}, 0,0,0,0,0,0,0,0, \omega_{4}, \\
0,0,0,0,0,0,0,0,0,0,0,0
\end{array}\right)^{\mathrm{T}} .
$$

When the mechanism contains mixed clearances, constraint equations could be obtained as

$$
\Phi(\mathbf{q}, t)=\left(\begin{array}{c}
x_{1}-L_{s 1} \cos \theta_{1} \\
y_{1}-L_{s 1} \sin \theta_{1} \\
x_{4}-L_{s 4} \cos \theta_{4} \\
y_{4}-L_{s 4} \sin \theta_{4}+L_{5} \\
\cos \left(\theta_{7}-\beta_{1}\right)-x_{2}-L_{s 2} \cos \theta_{2} \\
x_{7}+L_{s 72} \sin \left(\theta_{7}-\beta_{1}\right)-y_{2}-L_{s 2} \sin \theta_{2} \\
y_{7}+L_{s 72} \cos \left(\theta_{7}-\beta_{1}\right)-x_{3}-L_{s 3} \cos \theta_{3} \\
x_{7}+L_{s 72} \sin \left(\theta_{7}-\beta_{1}\right)-y_{3}-L_{s 3} \sin \theta_{3} \\
y_{7}+L_{s 72} x_{6}-L_{s 6} \cos \theta_{6}-H_{x} \\
y_{6}-L_{s 6} \sin \theta_{6}-H_{y} \\
x_{7}-L_{s 71} \cos \left(\theta_{7}+\beta\right)-x_{6}-L_{s 6} \cos \theta_{6} \\
y_{7}-L_{s 71} \sin \left(\theta_{7}+\beta\right)-y_{6}-L_{s 6} \sin \theta_{6} \\
x_{7}+L_{s 73} \cos \left(\theta_{7}+\beta_{12}+\omega_{12}\right)-x_{8}+L_{s 8} \cos \theta_{8} \\
y_{7}+L_{s 73} \sin \left(\theta_{7}+\beta_{12}+\omega_{12}\right)-y_{8}+L_{s 8} \sin \theta_{8} \\
x_{9}-H_{x}-L_{6} \cos \theta_{6}-L_{72} \cos \left(\theta_{7}+\beta_{12}\right)-L_{s 8} \cos \theta_{8} \\
y_{9}-H_{y}-L_{6} \sin \theta_{6}-L_{72} \sin \left(\theta_{7}+\beta_{12}\right)-L_{s 8} \sin \theta_{8} \\
\theta_{1}-\omega_{1} t-5.7645 \\
\theta_{4}-\omega_{4} t+2.4934 \\
\quad \mathbf{m}
\end{array}\right.
$$

When $t=0$, the initial centroid coordinate of the component, angle of component, structural size, and driving speed are brought into equation (26), and the vector of numerical values of constraint equations in initial configuration could be written as the following equation:

$$
\Phi(\mathbf{q}, 0)=\left(\begin{array}{c}
-2.5225 \times 10^{-6}, 2.5454 \times 10^{-5}, 4.0049 \times 10^{-5}, 4.3730 \times 10^{-6}, \\
3.0165 \times 10^{-4}, 6.1711 \times 10^{-5}, 1.8104 \times 10^{-4}, 3.4752 \times 10^{-4}, \\
4.1580 \times 10^{-6}, 2.1662 \times 10^{-5}, 1.7526 \times 10^{-4}, 1.5714 \times 10^{-5}, \\
4.4567 \times 10^{-4}, 6.2238 \times 10^{-4}, 2.2397 \times 10^{-5}, 4.0075 \times 10^{-6}, 0,0
\end{array}\right)^{\mathrm{T}}
$$

Taking the first derivative of equation (26) with respect to time, the following is obtained:

$$
\Phi_{q} \dot{q}=-\Phi_{t} \equiv v
$$

where $\boldsymbol{\Phi}_{q}$ is the Jacobian matrix and $\boldsymbol{\Phi}_{q}=\partial \boldsymbol{\Phi} / \partial \mathbf{q}, \boldsymbol{\Phi}_{t}$ is the derivative of constraint equation to time:

$$
\Phi_{t}=\frac{\partial \Phi}{\partial t}=\left[\begin{array}{c}
0_{16 \times 1} \\
-\omega_{1} \\
-\omega_{4}
\end{array}\right]
$$

Taking the second derivative of equation (26) with respect to time, the following is obtained:

$$
\Phi_{q} \ddot{q}=-\left(\Phi_{q} \dot{q}\right)_{q} \dot{q}-2 \Phi_{q t} \dot{q}-\Phi_{t t} \equiv \gamma .
$$

Dynamic equations could be written as [44-46]

$$
\mathbf{M} \ddot{q}+\Phi_{q}^{\mathrm{T}} \boldsymbol{\lambda}=\mathbf{g}
$$

where $\mathbf{M}, \boldsymbol{\lambda}$, and $\mathbf{g}$ are the mass matrix, Lagrange multiplier vector, and generalized force vector of the whole system, respectively. The generalized force consists of gravity and collision force at the clearance pairs. The normal contact force and tangential contact force at translational clearance 
adopt the force model described in Section 2.2. The normal contact force and tangential contact force at revolute clearances are modeled as described in Section 3.2.

The multibody dynamical equation with a single translational clearance and two revolute clearances in differential algebraic form is given by

$$
\left(\begin{array}{cc}
\mathbf{M} & \boldsymbol{\Phi}_{q}^{\mathrm{T}} \\
\boldsymbol{\Phi}_{q} & \mathbf{0}
\end{array}\right)\left(\begin{array}{l}
\ddot{q} \\
\boldsymbol{\lambda}
\end{array}\right)=\left(\begin{array}{l}
\mathbf{g} \\
\boldsymbol{\gamma}
\end{array}\right) \text {. }
$$

A more effective method is the default stability algorithm proposed by Baumgarte. In this method, displacement constraints and velocity constraints are introduced into the acceleration constraints equation by feedback control theory so as to reduce the default of the system $[11,26,33,47]$. So it is applied

$$
\left(\begin{array}{cc}
\mathbf{M} & \boldsymbol{\Phi}_{q}^{\mathrm{T}} \\
\boldsymbol{\Phi}_{q} & \mathbf{0}
\end{array}\right)\left(\begin{array}{c}
\ddot{q} \\
\boldsymbol{\lambda}
\end{array}\right)=\left(\begin{array}{c}
\mathbf{g} \\
\boldsymbol{\gamma}-2 \alpha \dot{\boldsymbol{\Phi}}-\beta^{2} \boldsymbol{\Phi}
\end{array}\right)
$$

where $\alpha$ and $\beta$ are the correction parameters and $\dot{\Phi}=\mathrm{d} \Phi / \mathrm{d} t$.

\section{Analysis of Dynamic Response}

The equation of motion (equation (33)) of the 2-DOF ninebar multilink mechanism with mixed clearances is solved through the Runge-Kutta method. Effects of various friction models, clearance value, and driving velocity on dynamical responses are all researched.

5.1. System Parameters. System parameters of mechanism considering mixed clearances are shown in Tables 1-3.

For the cranks 1 and 4 and links 2, 3, 6, and 8 , $L_{s i}=(1 / 2) L_{i}(i=1,2,3,4,6,8)$.

\subsection{Effect of Different Friction Models on Dynamics Responses} with Mixed Clearances. Driving speeds of cranks are set as $\omega_{1}=-2 \pi(\mathrm{rad} / \mathrm{s})$ and $\omega_{4}=2 \pi(\mathrm{rad} / \mathrm{s})$ and clearance values of pairs $A, B$, and $C$ are all set as $0.4 \mathrm{~mm}$. For investigating the effect of different friction models on dynamics, the modified Coulomb friction and LuGre models are discussed. Acceleration, contact force of the slider, contact forces of revolute clearances, driving torques, and slider trajectory are shown in Figure 7.

Instability may occur in the first two periods of calculation. Therefore, the data of the first two periods are discarded, and then, the data of two periods are taken to draw the dynamic response curves.

As illustrated in Figure 7, influences of the LuGre and modified Coulomb friction models on dynamic responses for the 2-DOF nine-bar mechanism are slightly different. When the LuGre model is applied, vibration is more obvious than that of the modified Coulomb model. There are also some differences in values of dynamic responses. When the LuGre model is applied, the value of dynamic responses is bigger than that of the modified Coulomb friction model.
TAвLE 1: Geometric and inertial parameters.

\begin{tabular}{lcccc}
\hline Component & Symbol & $L(\mathrm{~m})$ & $m(\mathrm{~kg})$ & $J\left(10^{-3} \mathrm{~kg} \cdot \mathrm{m}^{2}\right)$ \\
\hline Crank 1 & $L_{1}$ & 0.045 & 0.148 & 0.2382 \\
Link 2 & $L_{2}$ & 0.326 & 0.805 & 8.001 \\
Link 3 & $L_{3}$ & 0.497 & 0.603 & 13.37 \\
Crank 4 & $L_{4}$ & 0.095 & 0.265 & 1.210 \\
Link 5 & $L_{5}$ & 0.430 & - & - \\
Link 6 & $L_{6}$ & 0.230 & 0.581 & 12.12 \\
& $L_{71}$ & 0.325 & & \\
Triangular member 7 & $L_{72}$ & 0.250 & 4.334 & 38.02 \\
& $L_{73}$ & 0.386 & & \\
Link 8 & $L_{8}$ & 0.335 & 0.827 & 8.663 \\
Slider 9 & - & - & 0.801 & - \\
\hline
\end{tabular}

TABle 2: Parameters.

\begin{tabular}{lc}
\hline Parameter & Parameter values \\
\hline$\beta[\mathrm{rad}]$ & 0.5954 \\
$\beta_{1}[\mathrm{rad}]$ & 0.3878 \\
$\beta_{12}[\mathrm{rad}]$ & 1.4528 \\
$\omega_{12}[\mathrm{rad}]$ & 0.6316 \\
$L_{s 71}[\mathrm{~m}]$ & 0.147 \\
$L_{s 72}[\mathrm{~m}]$ & 0.219 \\
$L_{s 73}[\mathrm{~m}]$ & 0.190 \\
$H_{x}[\mathrm{~m}]$ & 0.645 \\
$H_{y}[\mathrm{~m}]$ & 0.08 \\
\hline
\end{tabular}

TABle 3: Clearance joints' parameters.

\begin{tabular}{lc}
\hline Parameter & Parameter values \\
\hline Length of slider $L(\mathrm{~mm})$ & 50 \\
Width of slider $W(\mathrm{~mm})$ & 50 \\
Slider thickness $T(\mathrm{~mm})$ & 35 \\
Distance between guide surfaces $H(\mathrm{~mm})$ & 70 \\
Coefficient of restitution $c_{e}$ & 0.9 \\
Bearing radius $R_{1}(\mathrm{~mm})$ & 15 \\
Poisson ratio $v_{m}, v_{n}, v_{i}, v_{j}$ & 0.3 \\
Integral step $(\mathrm{s})$ & 0.0001 \\
Corner curvature radius $R_{m n}(\mathrm{~mm})$ & 1 \\
Elastic modulus $E_{m}, E_{n}, E_{i}, E_{j}(\mathrm{GPa})$ & 207 \\
Bristle stiffness $\widetilde{\xi}_{0}(\mathrm{~N} / \mathrm{m})$ & 100000 \\
Viscous friction coefficient $\widetilde{\xi}_{2}$ & 0 \\
Stribeck velocity $\widetilde{v}_{s}$ & $1 \%$ of maximum $v_{t}$ \\
Microscopic damping coefficient $\widetilde{\xi}_{1}(\mathrm{Ns} / \mathrm{m})$ & 400 \\
Gradient of friction decay $\widetilde{\gamma}_{\text {Baumgarte stabilization coefficient } \alpha}$ & 2 \\
Baumgarte stabilization coefficient $\beta$ & 5 \\
Relative tolerance & 5 \\
\hline
\end{tabular}

5.3. Influence of Different Clearance Values on Dynamics Responses with Mixed Clearances. For researching influence of clearance values on dynamic responses, slider's kinematic characteristics, contact forces at revolute clearance pairs, contact force of the slider, driving torques, shaft center trajectories at revolute clearance pairs, and slider trajectory inside the guide are all studied, as shown in Figures 8-15. Assume that clearance values of revolute pairs $A$ and $B$ and translational pair $C$ are all same. Supposing that driving speeds of crank $1 \omega_{1}=-2 \pi(\mathrm{rad} / \mathrm{s})$ and crank $4 \omega_{4}=2 \pi(\mathrm{rad} / \mathrm{s})$, the 


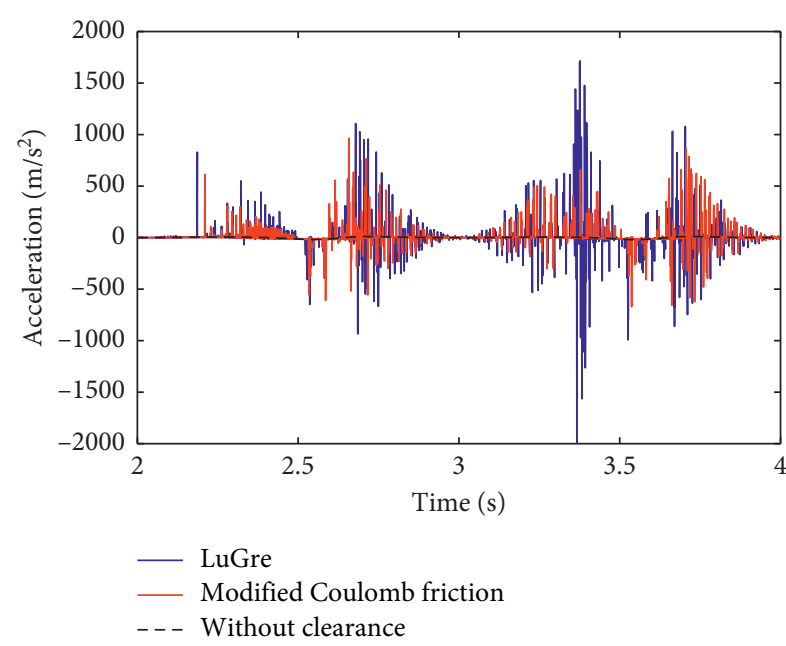

(a)

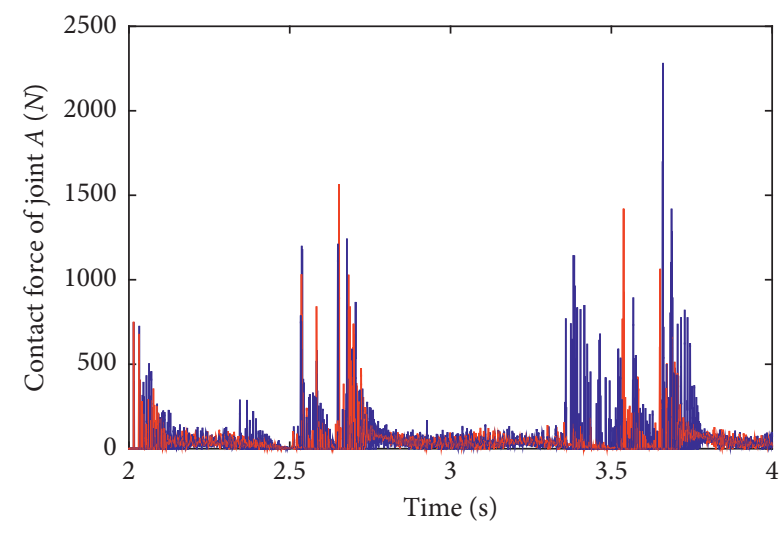

- LuGre

_ Modified Coulomb friction

(c)

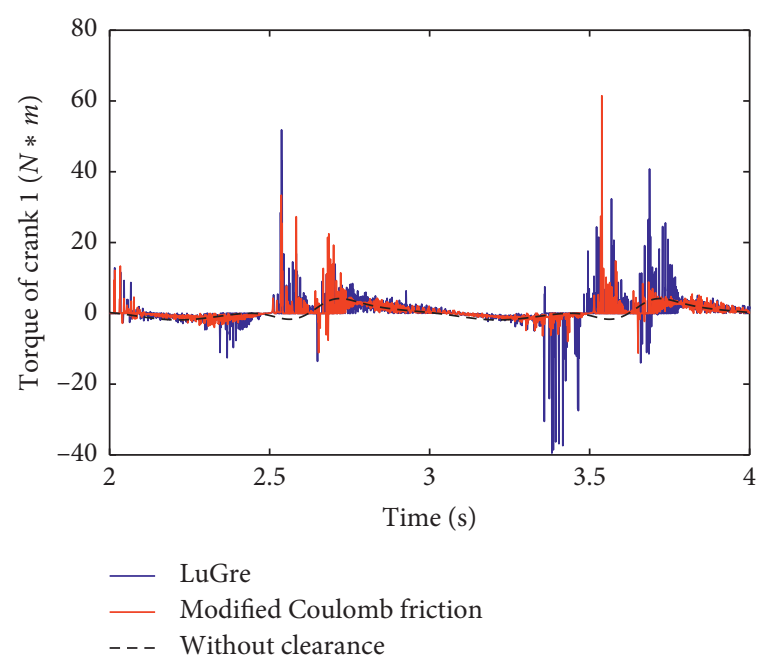

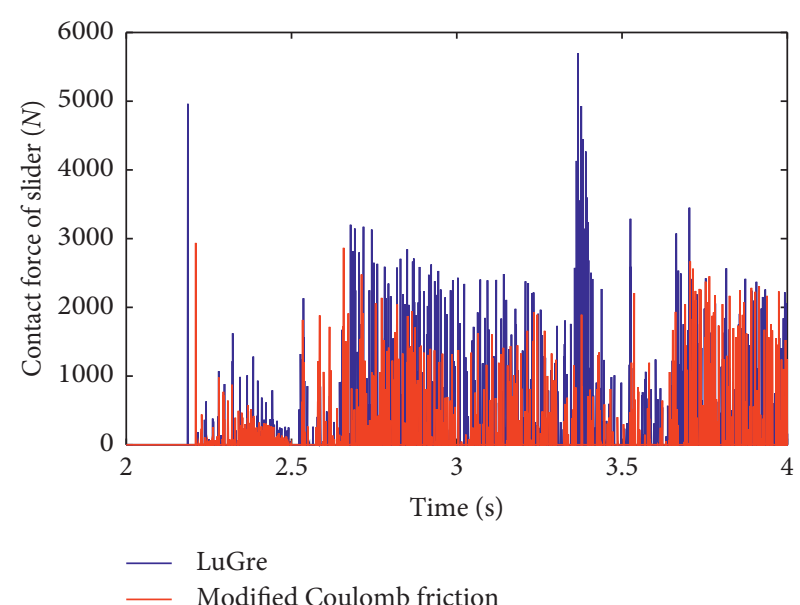

(b)

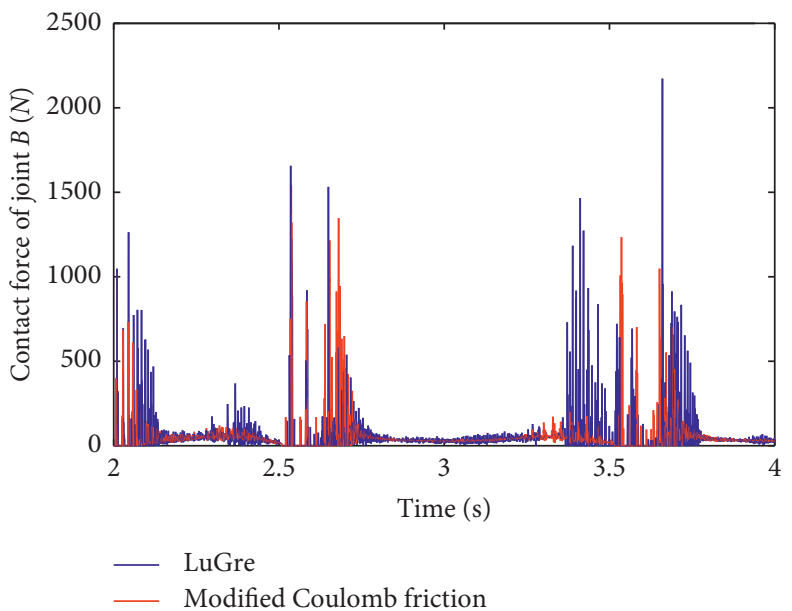

(d)

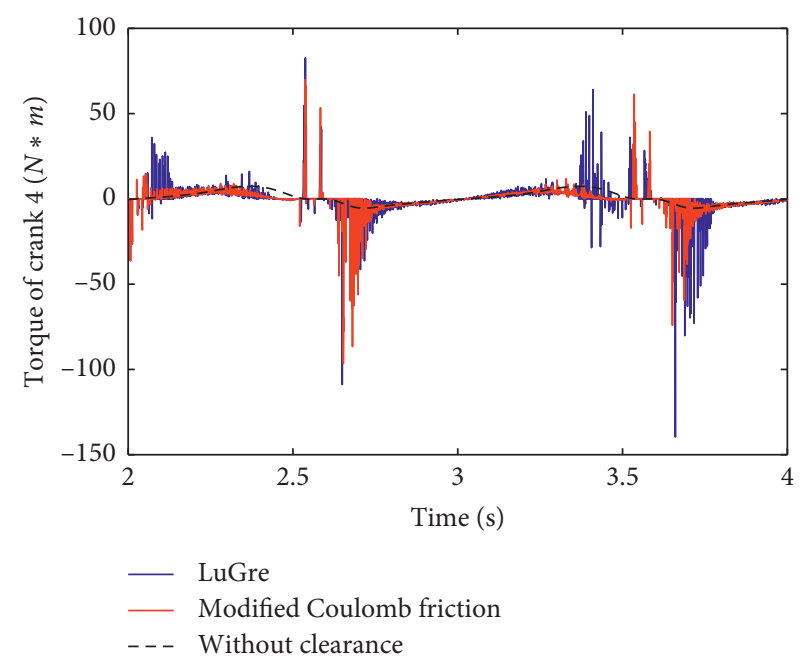

(f)

Figure 7: Continued. 


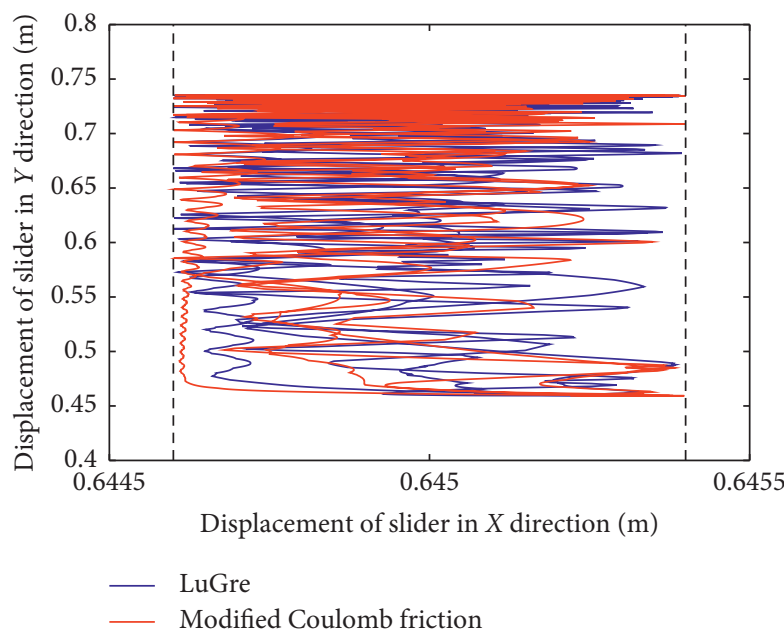

(g)

FIGURe 7: Dynamic response with mixed clearances for different friction models. (a) Acceleration of slider. (b) Contact force of slider. (c) Contact force at pair A. (d) Contact force at pair B. (e) Driving torque of crank 1. (f) Driving torque of crank 4. (g) Slider trajectory inside the guide.

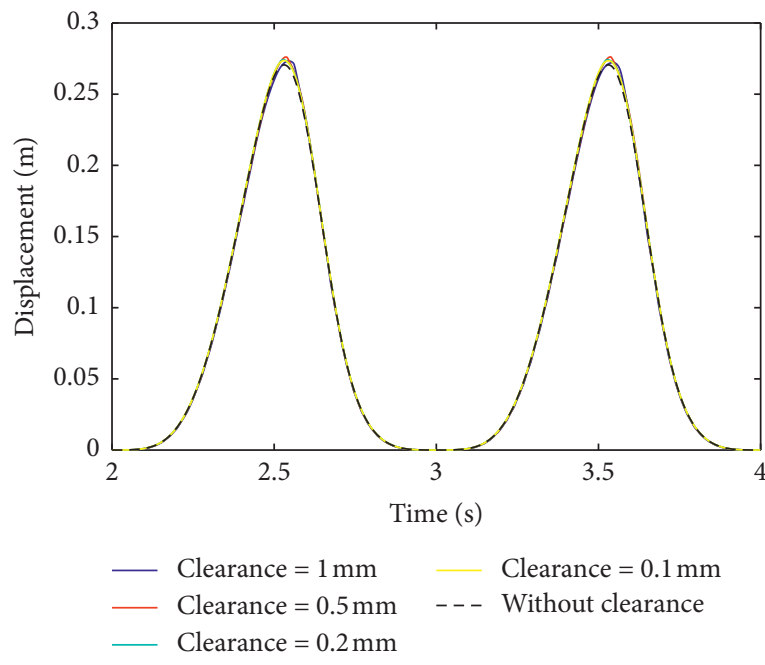

(a)

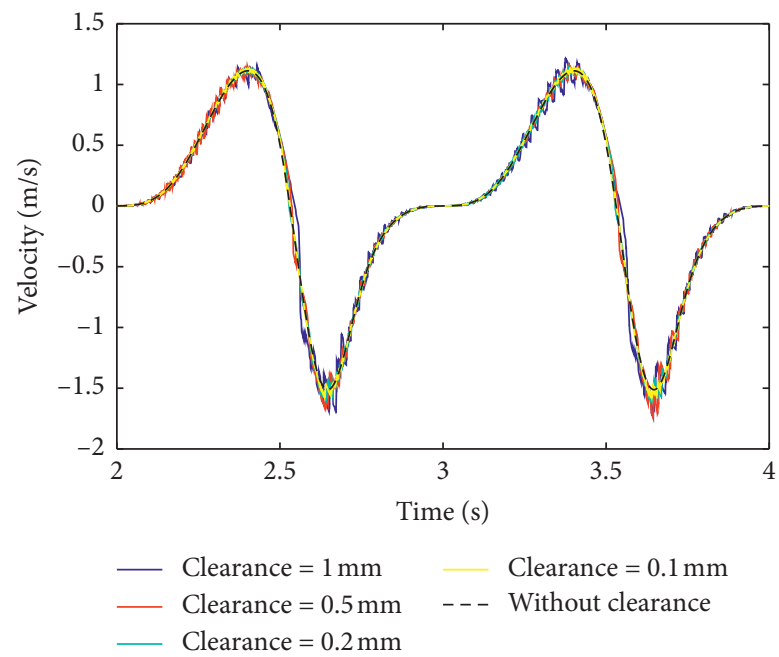

(b)

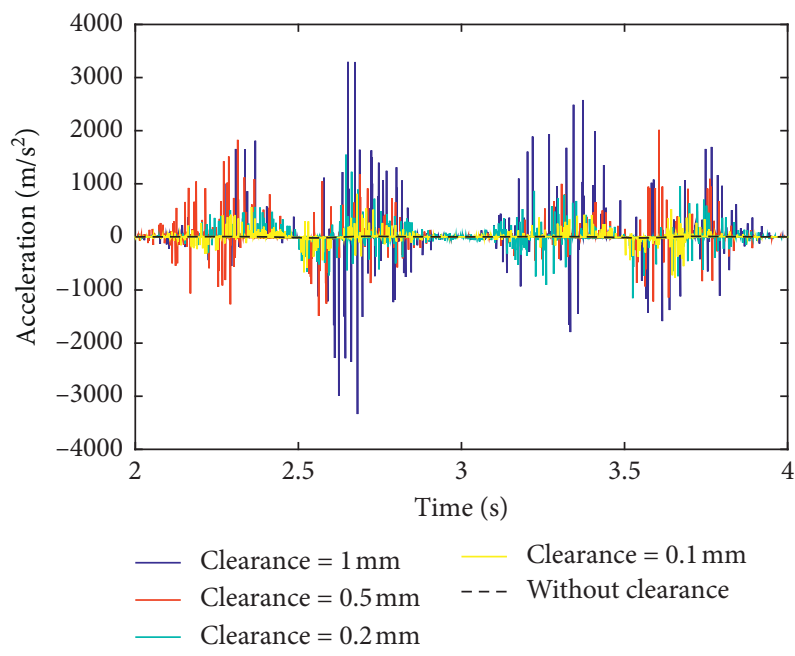

(c)

Figure 8: Kinematics characteristics of the slider. (a) Displacement of the slider. (b) Velocity of the slider. (c) Acceleration of the slider. 

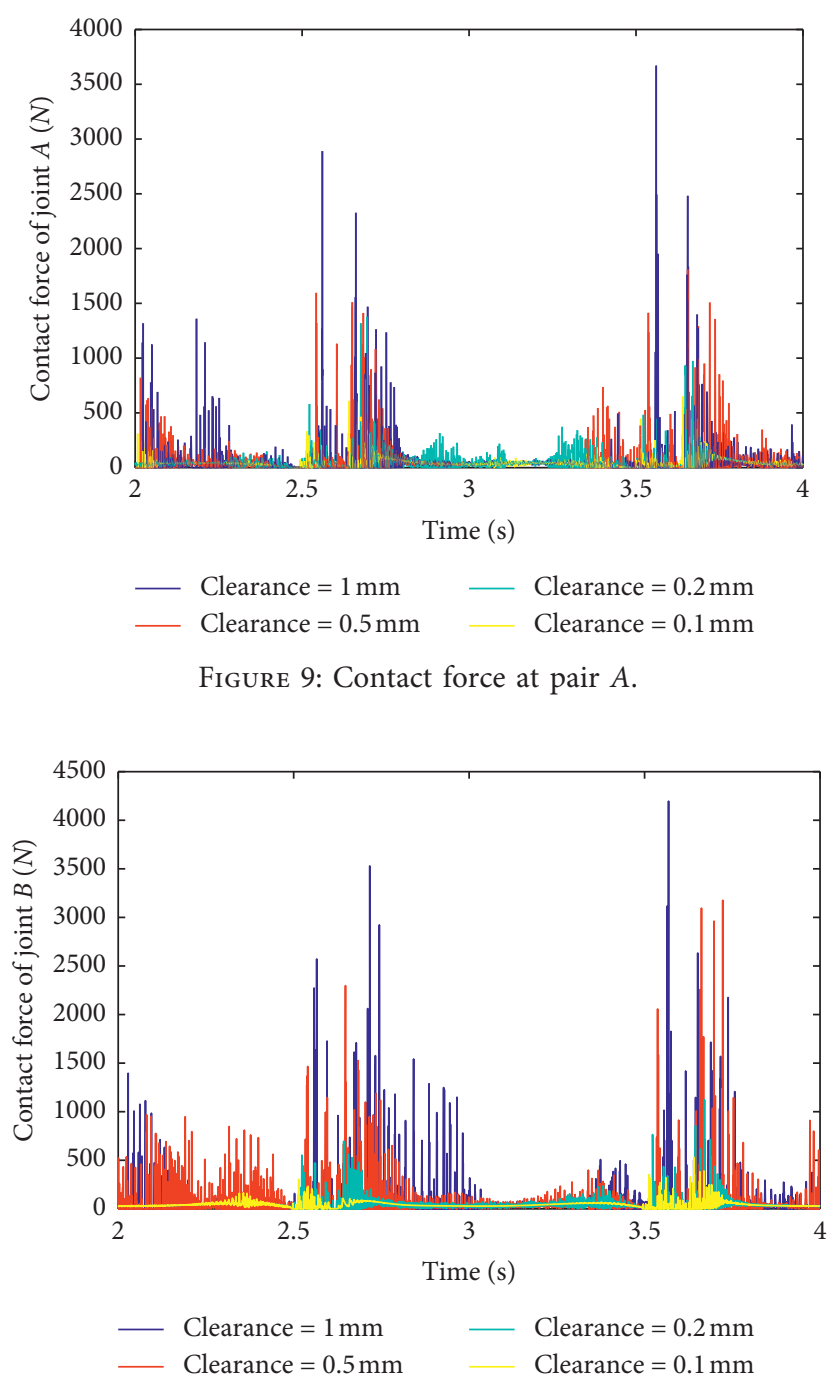

Figure 10: Contact force at pair $B$.

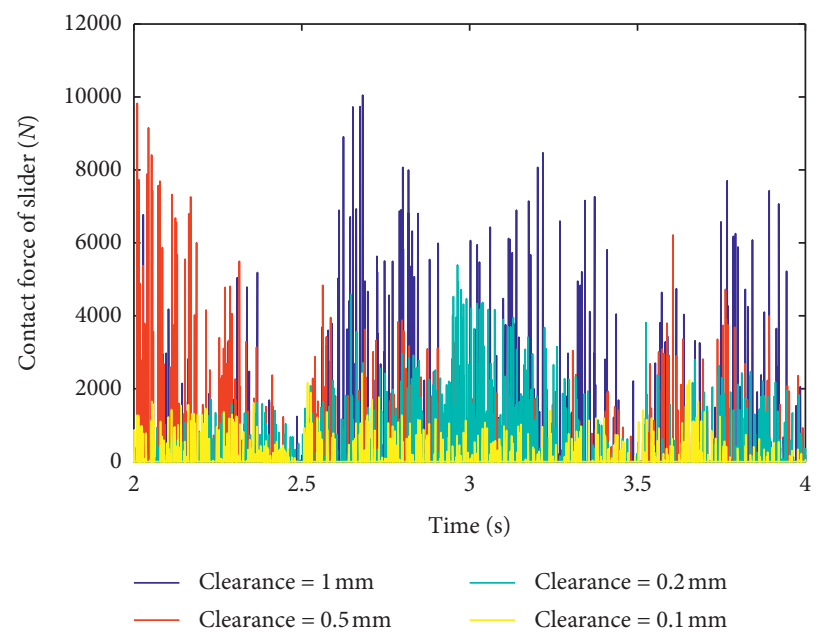

Figure 11: Contact force of the slider.

effects of different clearance values on dynamics with mixed clearances are all analyzed, and clearance values are chosen as $0.1 \mathrm{~mm}, 0.2 \mathrm{~mm}, 0.5 \mathrm{~mm}$, and $1 \mathrm{~mm}$.
As illustrated in Figure 8(a), the clearances have little effect on the displacement curve, which is very close to the situation that all ideal joints are without clearances. As 


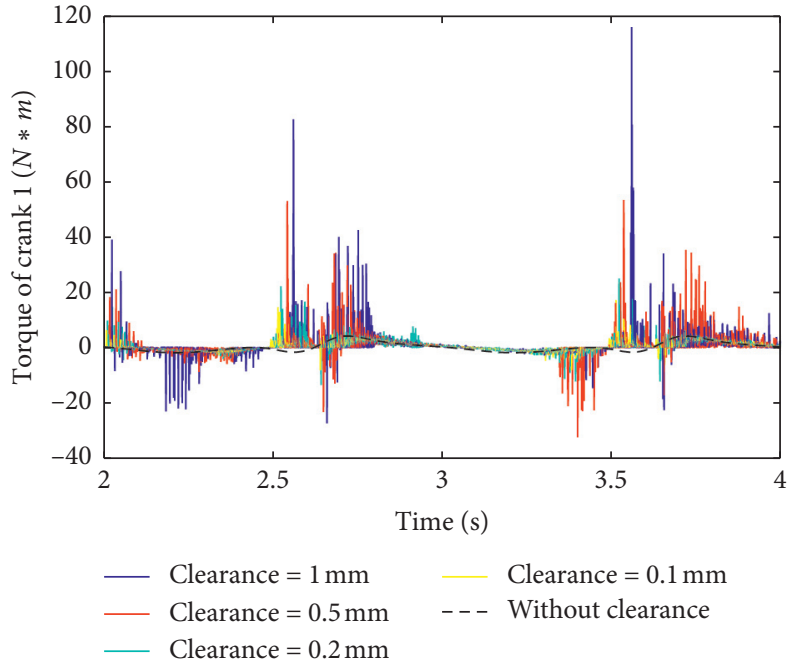

(a)

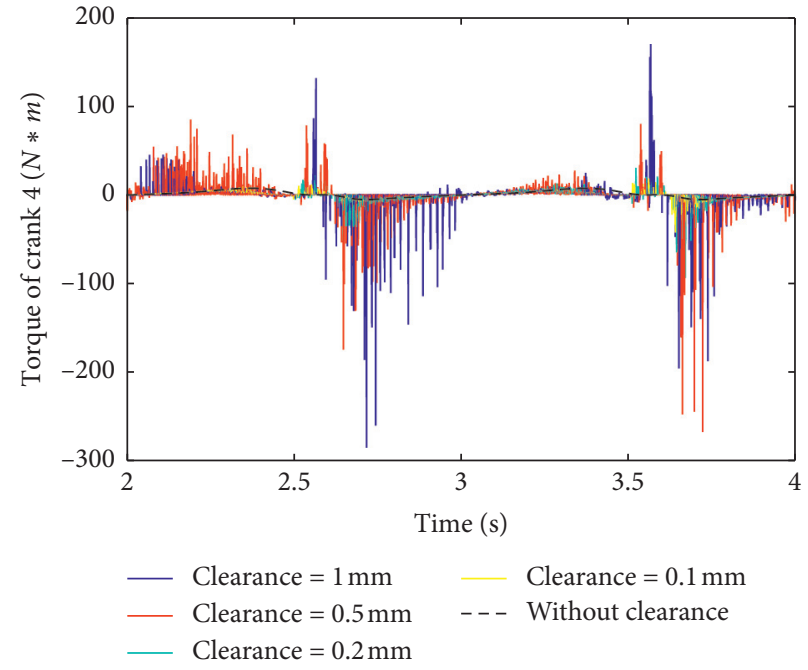

(b)

Figure 12: Driving torque of the crank. (a) Driving torque of crank 1. (b) Driving torque of crank 4.

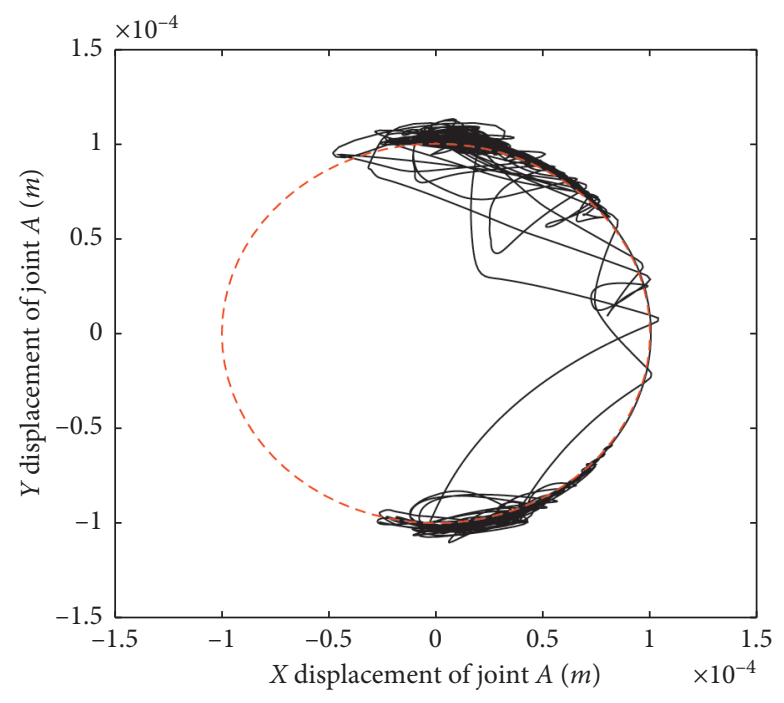

- Clearance $=0.1 \mathrm{~mm}$

(a)

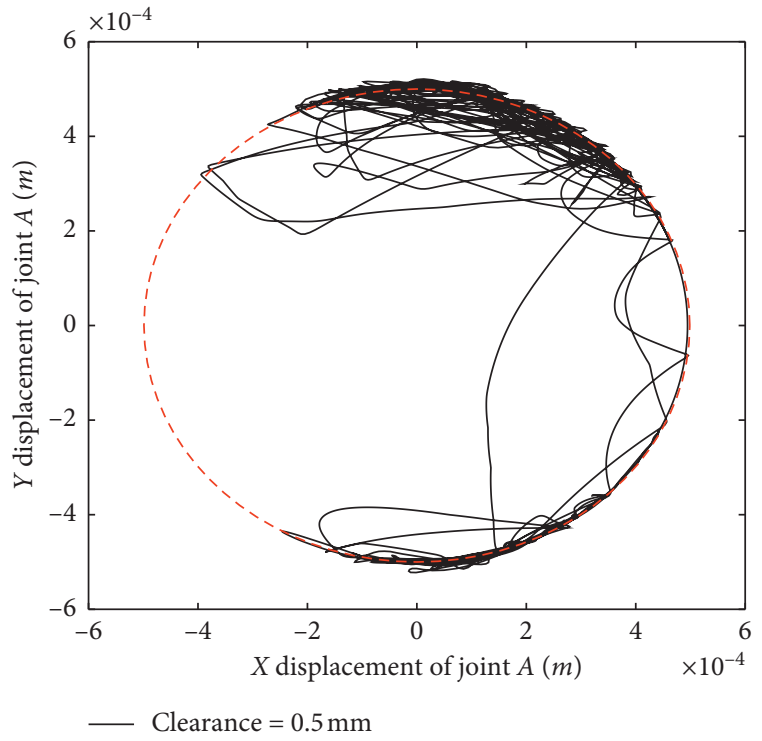

(b)

FiguRe 13: Shaft center trajectory at pair $A$.

shown in Figure 8(b), as there is an increase in the clearance value at revolute joints and translational joints, the vibration of the velocity curve becomes more and more severe. Existence of clearance has a relatively high effect on acceleration, contact forces at revolute pairs, contact force of the slider, and driving torque of cranks, as displayed in Figures $8(\mathrm{c})-12$. Moreover, its peak and vibration frequency both increase with increase of the clearance value. Driving torques of cranks are mainly affected by collision forces at clearance joints $A$ and $B$. The vibration of driving torque is consistent with contact force vibration at $A$ and $B$ clearance pairs. As displayed in Figures 8(c) and 11, the frequency of vibration and the time point of peak value of slider's acceleration are basically consistent with the contact force of the slider. It could be seen that contact force of the slider directly affects the slider's acceleration.

If the clearance values $0.1 \mathrm{~mm}, 0.2 \mathrm{~mm}, 0.5 \mathrm{~mm}$, and $1 \mathrm{~mm}$ are considered to discuss the effect of clearance value on the shaft center trajectory and slider trajectory inside the guide, there are too many pictures in this paper, so $0.1 \mathrm{~mm}$ and $0.5 \mathrm{~mm}$ are selected. From Figures 13-15, with increase of clearances, chaos of trajectories become more and more serious. The reason is that the bigger the clearance value is, the more serious impact happens and the more chaotic slider trajectory inside the guide is. When the clearance value is small, the dynamic response is smooth and close to situation 


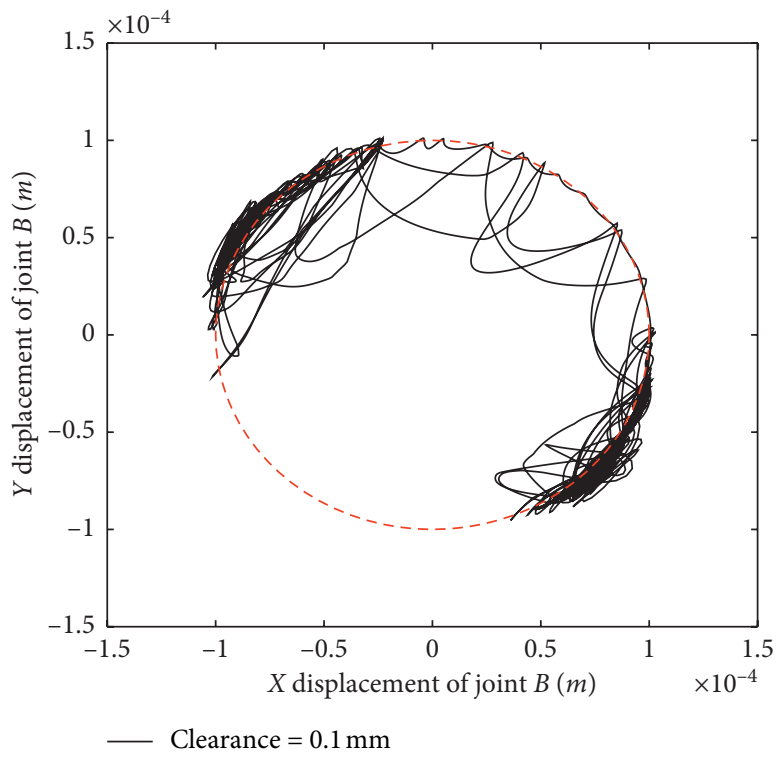

(a)

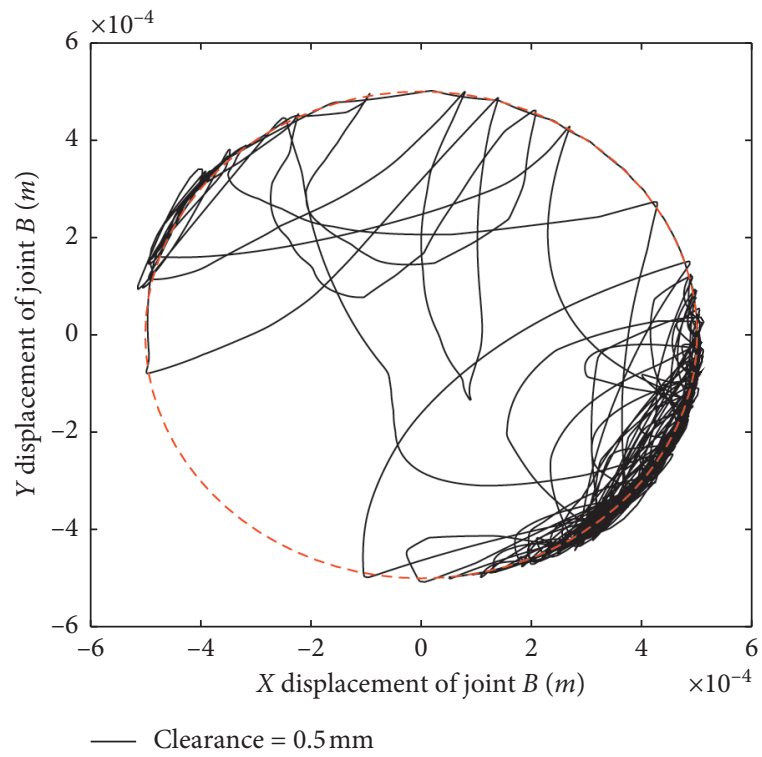

(b)

FIGURE 14: Shaft center trajectory at pair $B$.

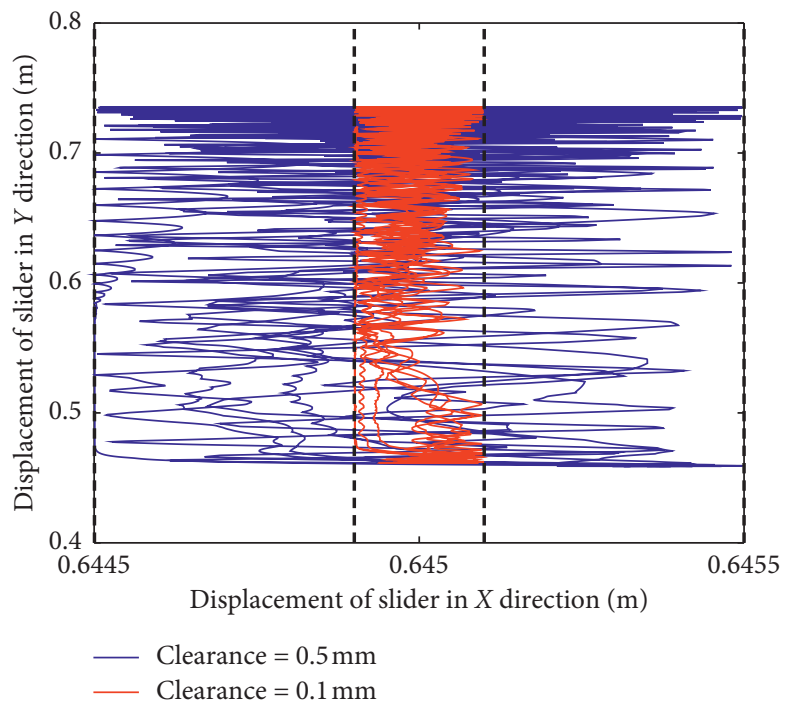

FIgURE 15: Slider trajectory inside the guide.

that all ideal joints are without clearances. It is suggested that continuous contact state between the slider and the guide is longer; therefore, fewer impacts exist on the slider and the guide.

\subsection{Effect of Different Driving Velocity on Dynamics Responses} with Mixed Clearances. Clearance values of revolute $A$, revolute $B$, and translational pair $C$ are all defined as $0.25 \mathrm{~mm}$. Driving speed of cranks 1 and 4 is assumed as $-2.5 \pi(\mathrm{rad} / \mathrm{s})$ and $2.5 \pi(\mathrm{rad} / \mathrm{s}),-5 \pi(\mathrm{rad} / \mathrm{s})$ and $5 \pi(\mathrm{rad} / \mathrm{s})$, respectively. Velocity, velocity error, and acceleration are displayed in Figures 16-18. As displayed in Figure 16, velocity is less affected by clearances and it is closer to the situation that all ideal joints are without clearances. However, according to Figure 17, it is shown that the velocity error increases with increase in the driving speed. As displayed in Figure 18, vibration of acceleration is more intense than slider's velocity. Moreover, the peak value of acceleration increases with increase in the driving speed.

The contact forces at pairs $A, B$, and contact force of the slider are shown in Figures 19-21. From Figures 19-21, it can be seen that, with the increase in the driving speeds of driving components, the peak value of contact forces at pairs $A$ and $B$ and contact force of the slider are both increased. The reason is that the greater the driving speed is, the more 


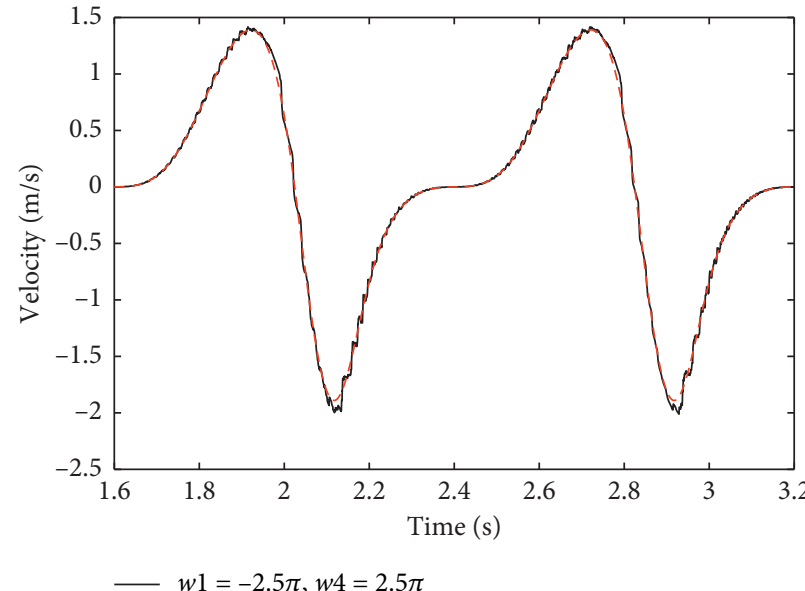

(a)

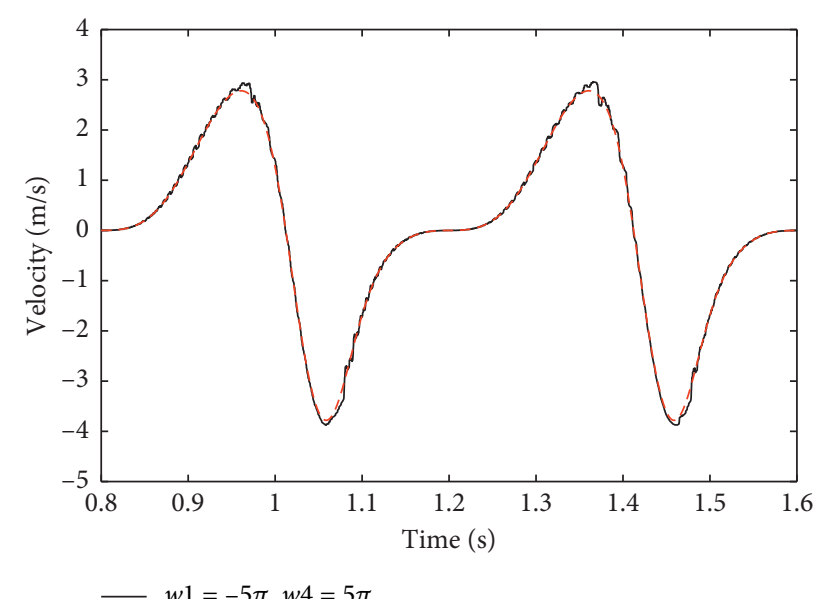

(b)

FIGURE 16: Velocity of the slider. (a) $\omega_{1}=-2.5 \pi(\mathrm{rad} / \mathrm{s}), \omega_{4}=2.5 \pi(\mathrm{rad} / \mathrm{s})$ and $(\mathrm{b}) \omega_{1}=-5 \pi(\mathrm{rad} / \mathrm{s}), \omega_{4}=5 \pi(\mathrm{rad} / \mathrm{s})$.

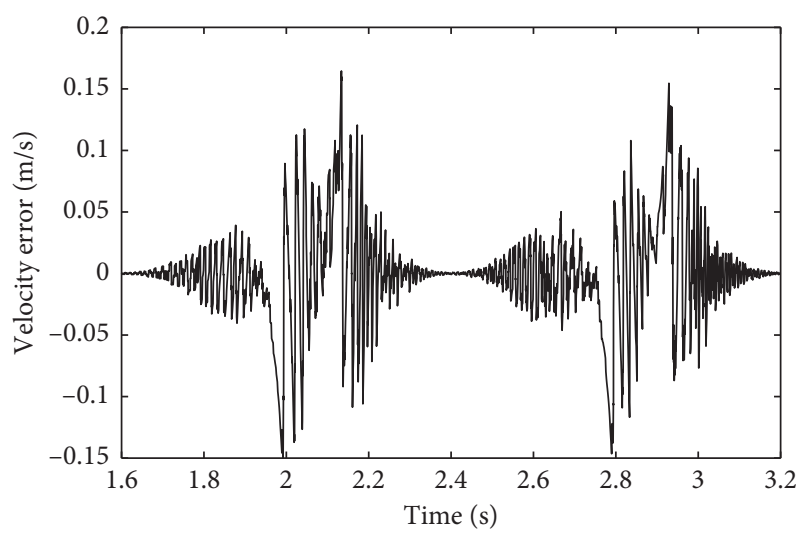

(a)

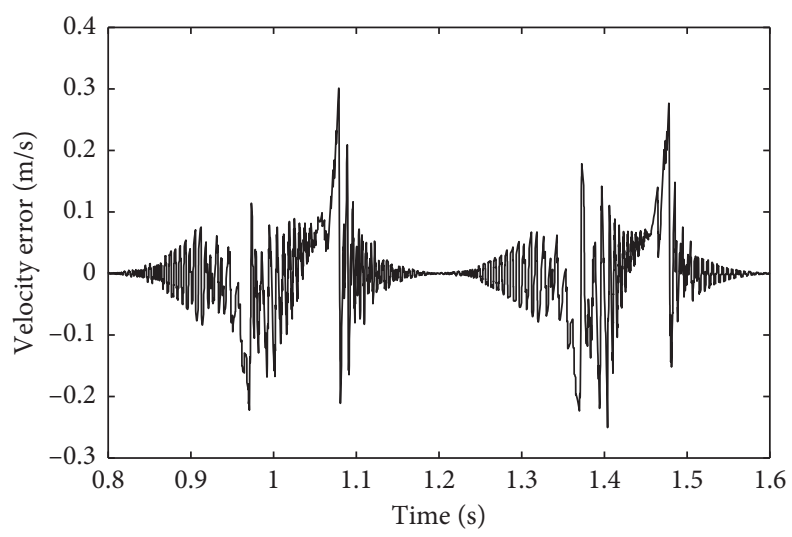

(b)

FIGURE 17: Velocity error of the slider. (a) $\omega_{1}=-2.5 \pi(\mathrm{rad} / \mathrm{s}), \omega_{4}=2.5 \pi(\mathrm{rad} / \mathrm{s})$ and (b) $\omega_{1}=-5 \pi(\mathrm{rad} / \mathrm{s}), \omega_{4}=5 \pi(\mathrm{rad} / \mathrm{s})$.

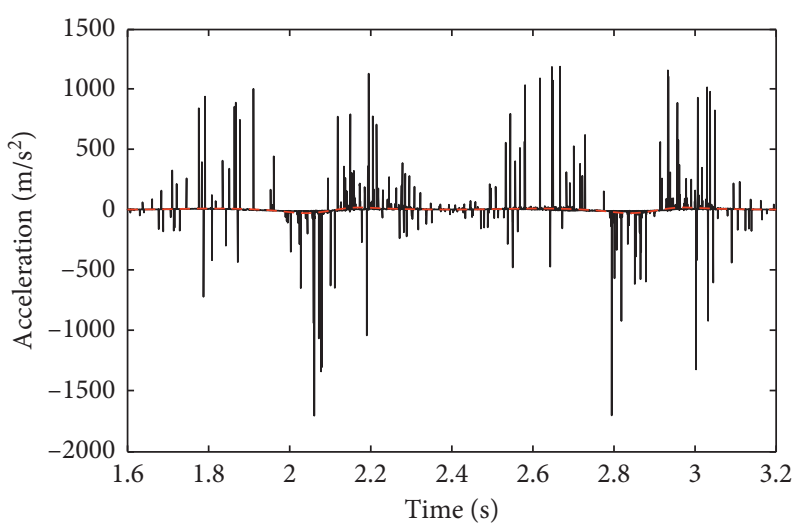

(a)

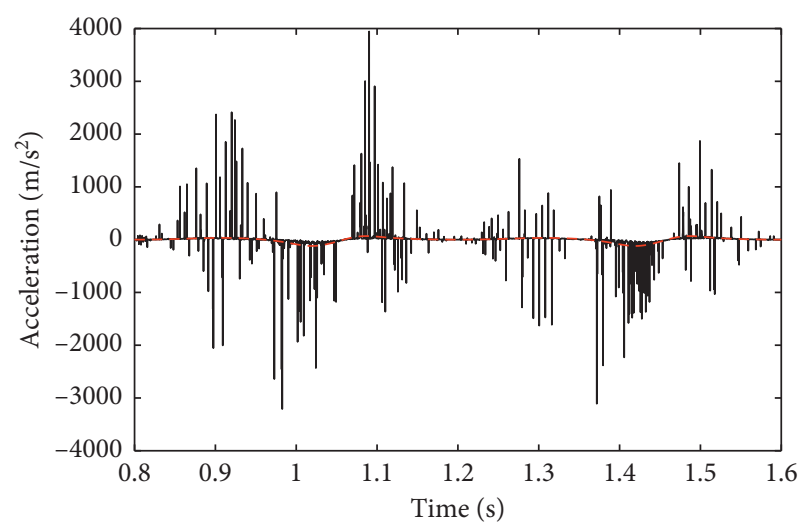

(b)

Figure 18: Acceleration of the slider. (a) $\omega_{1}=-2.5 \pi(\mathrm{rad} / \mathrm{s}), \omega_{4}=2.5 \pi(\mathrm{rad} / \mathrm{s})$ and (b) $\omega_{1}=-5 \pi(\mathrm{rad} / \mathrm{s}), \omega_{4}=5 \pi(\mathrm{rad} / \mathrm{s})$. 


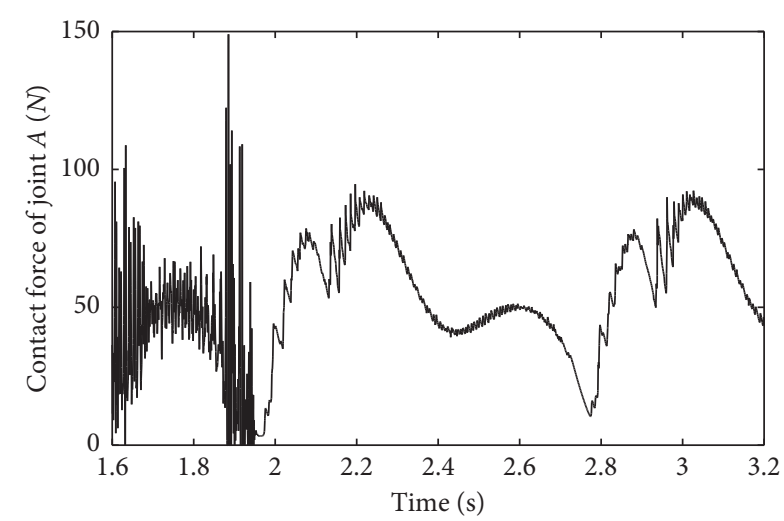

(a)

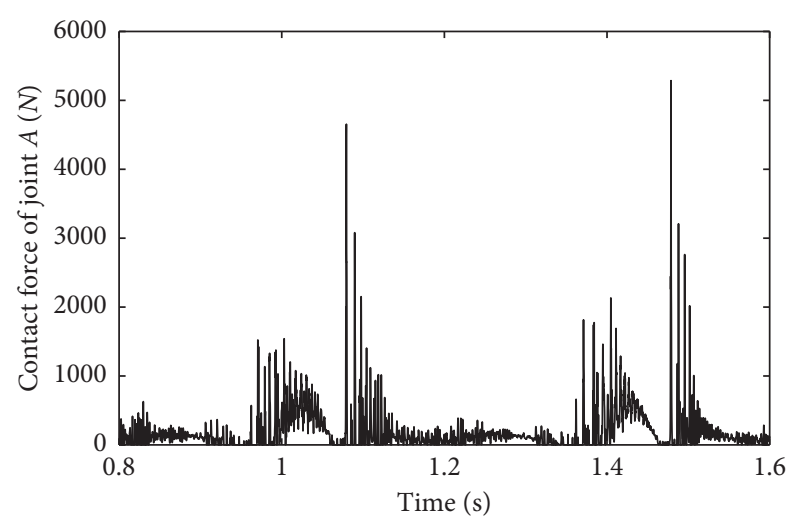

(b)

FIGURE 19: Contact force at pair $A$. (a) $\omega_{1}=-2.5 \pi(\mathrm{rad} / \mathrm{s}), \omega_{4}=2.5 \pi(\mathrm{rad} / \mathrm{s})$ and (b) $\omega_{1}=-5 \pi(\mathrm{rad} / \mathrm{s}), \omega_{4}=5 \pi(\mathrm{rad} / \mathrm{s})$.

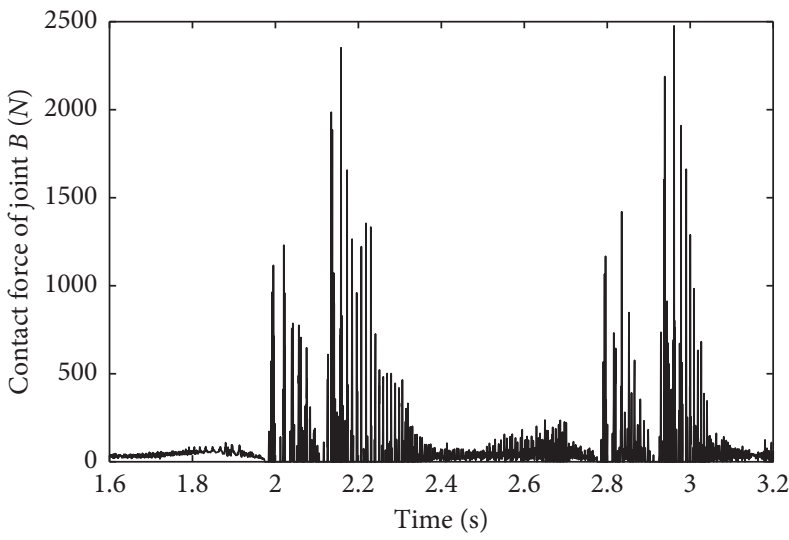

(a)

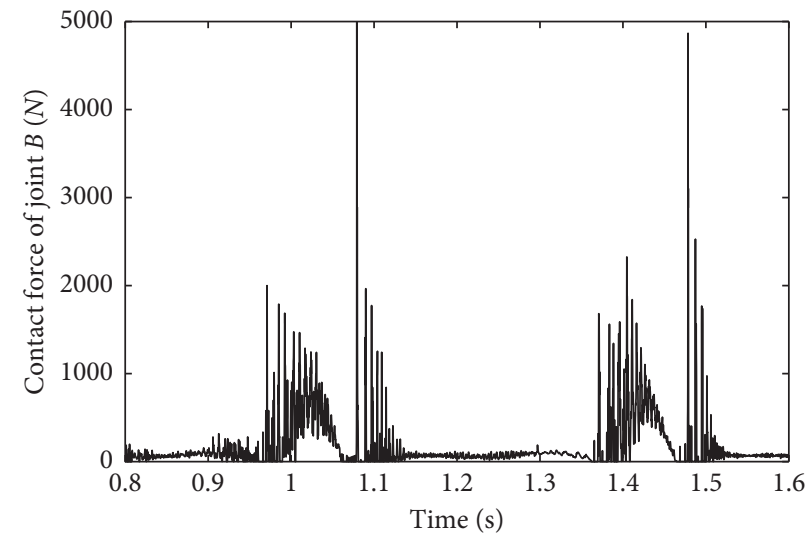

(b)

FIgure 20: Contact force at pair B. (a) $\omega_{1}=-2.5 \pi(\mathrm{rad} / \mathrm{s}), \omega_{4}=2.5 \pi(\mathrm{rad} / \mathrm{s})$ and (b) $\omega_{1}=-5 \pi(\mathrm{rad} / \mathrm{s}), \omega_{4}=5 \pi(\mathrm{rad} / \mathrm{s})$.

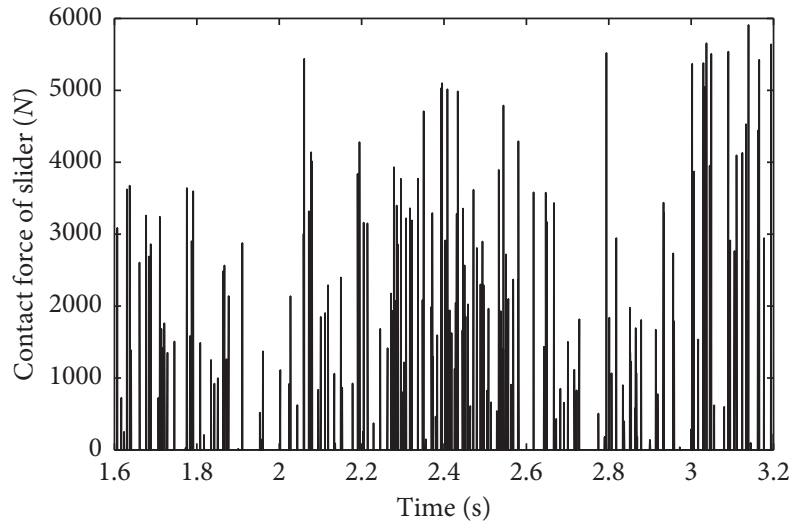

(a)

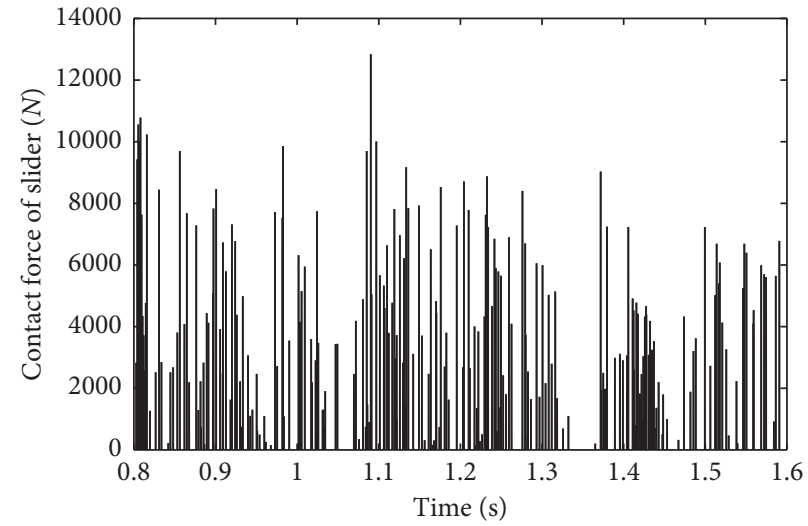

(b)

FIgURE 21: Contact force of the slider. (a) $\omega_{1}=-2.5 \pi(\mathrm{rad} / \mathrm{s}), \omega_{4}=2.5 \pi(\mathrm{rad} / \mathrm{s})$ and (b) $\omega_{1}=-5 \pi(\mathrm{rad} / \mathrm{s}), \omega_{4}=5 \pi(\mathrm{rad} / \mathrm{s})$.

severe the impact is and the greater the contact force is. Therefore, the maximum value of dynamic responses becomes larger and larger.
The shaft center trajectory of $A$, shaft center trajectory of $B$, and slider trajectory inside the guide are shown in Figures 22-24, respectively. Similarly, while the driving 


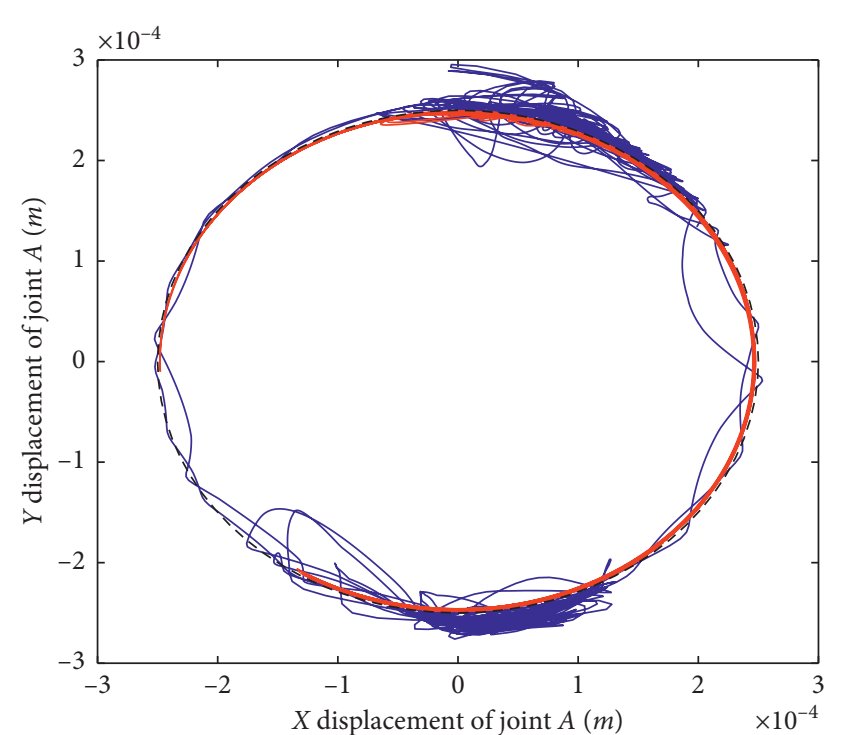

$\omega 1=-5 \pi, \omega 4=5 \pi$

$\omega 1=-2.5 \pi, \omega 4=2.5 \pi$

Figure 22: Shaft center trajectory at pair $A$.

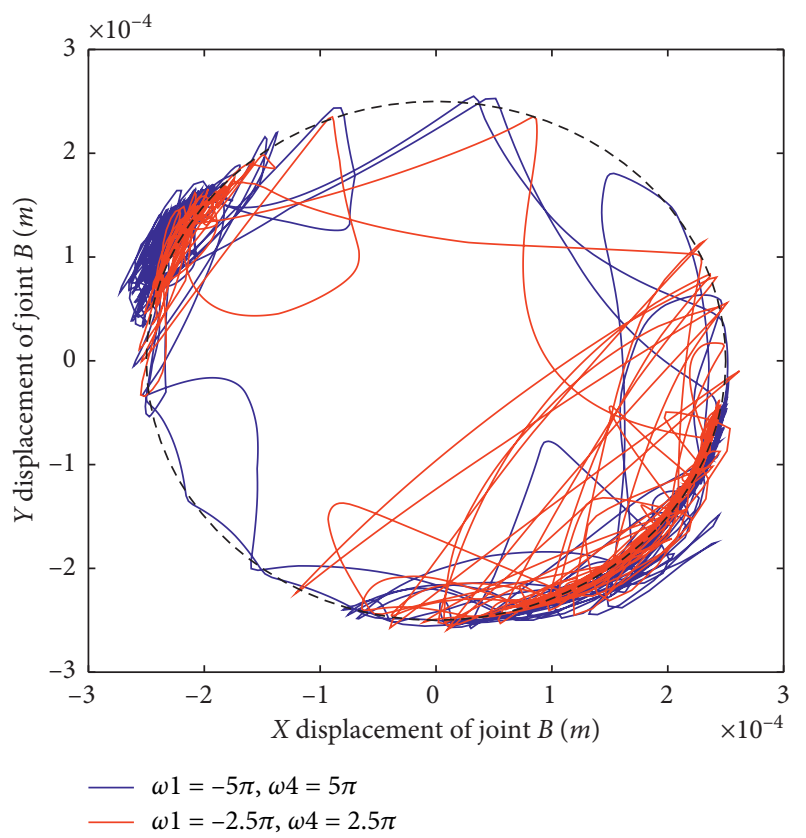

Figure 23: Shaft center trajectory at pair $B$.

speed increases, shaft center trajectory of $A$, shaft center trajectory of $B$, and slider trajectory inside the guide become more and more chaotic, and the collisions at clearance joints are more and more serious.

5.5. Virtual Simulation Results. For conforming correctness of the numerical result, a virtual prototype model of 2-DOF nine-bar mechanism with mixed clearances has been built through ADAMS. Clearance sizes of translational clearance and two revolute clearances are all assumed as $0.1 \mathrm{~mm}$, and

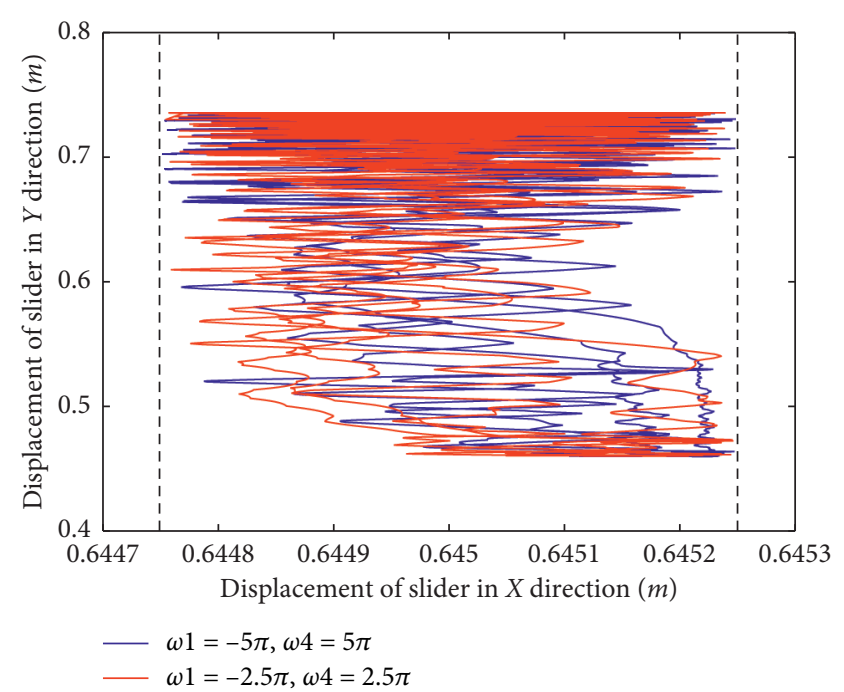

FIgURE 24: Slider trajectory inside the guide.

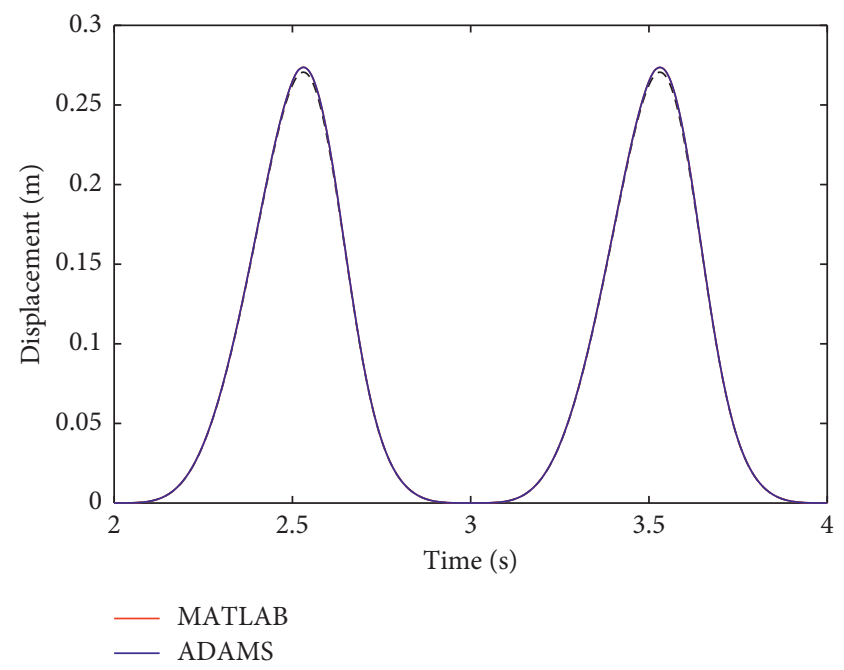

Figure 25: Displacement of the slider.

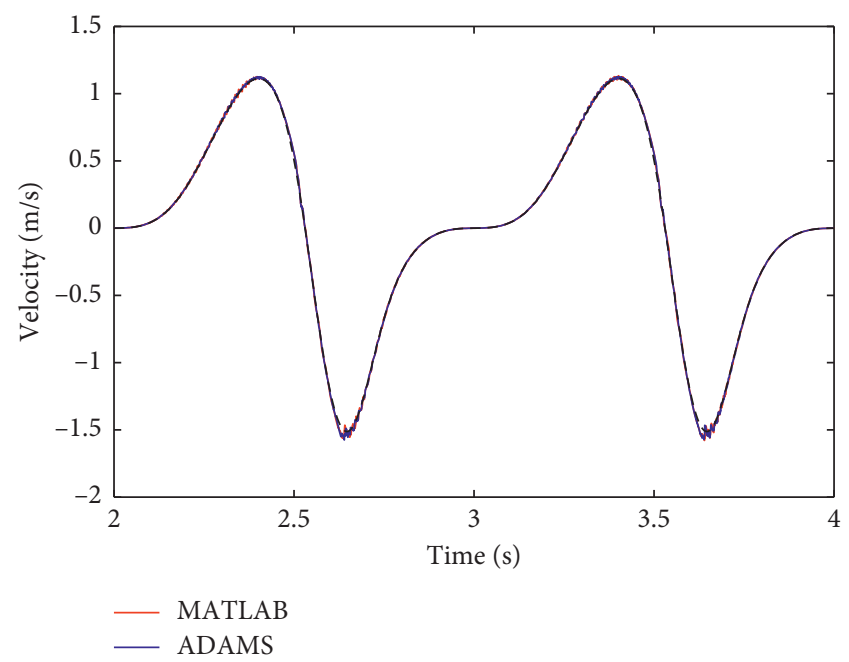

Figure 26: Velocity of the slider. 


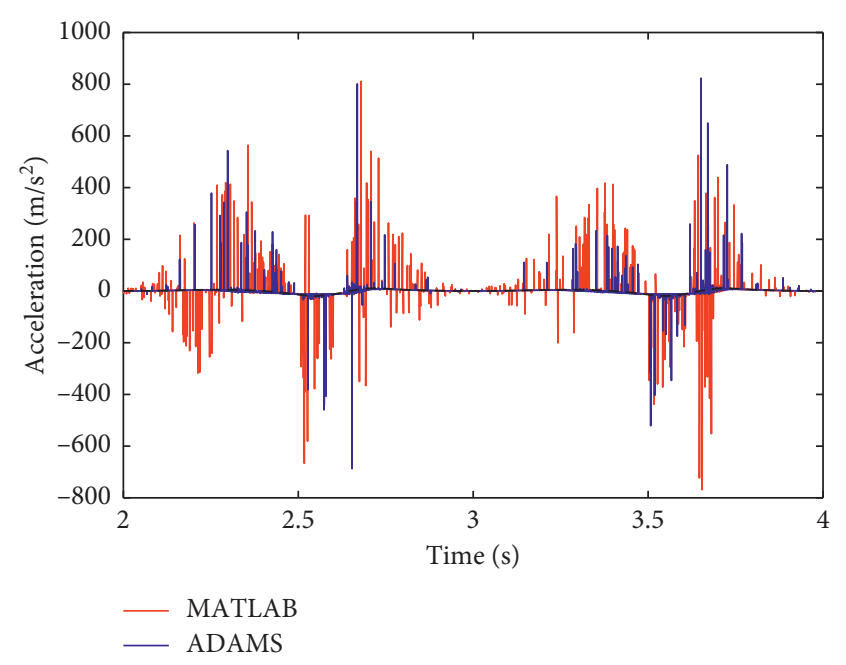

Figure 27: Acceleration of the slider.

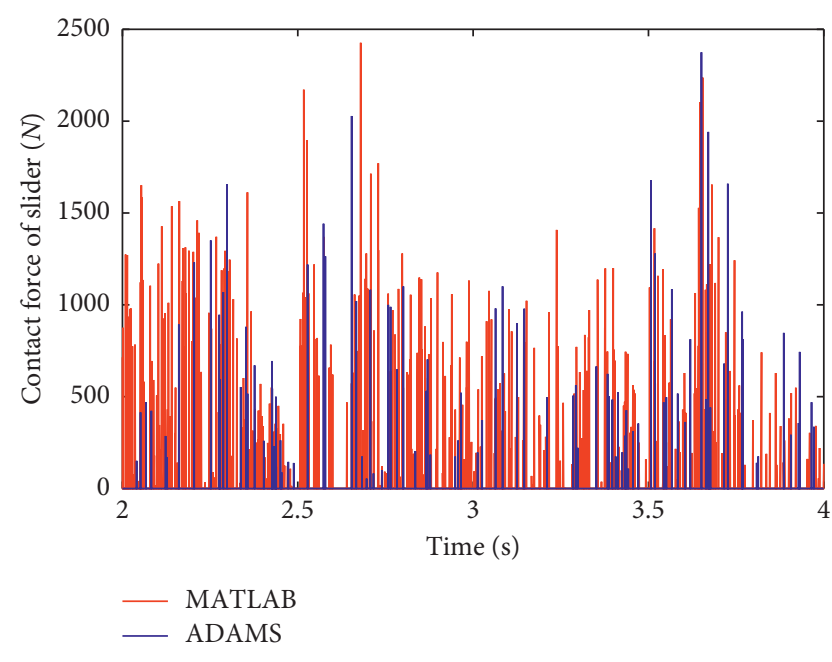

FIGURE 28: Contact force of the slider.

driving velocity of cranks 1 and 4 is set as $-2 \pi(\mathrm{rad} / \mathrm{s})$ and $2 \pi(\mathrm{rad} / \mathrm{s})$. Slider's displacement, velocity, acceleration, and contact force of the slider are shown in Figures 25-28.

From Figures 25-28, the result of ADAMS is slightly different from MATLAB. This is mainly due to the different modeling methods, solution methods, and integration errors [48], and they are also different in the way to identify contact between the slider and the guide. From Figures 25-28, it can be seen that the curves obtained by MATLAB and ADAMS are same in trend and have similar regularity, and the difference between the two curves is smaller; then, the correctness of the theoretical model can be proved.

\section{Conclusions}

This paper researches the dynamic responses of the 2-DOF nine-bar mechanism containing mixed clearances based on the LuGre model.

(1) Translational and the revolute clearance models are both developed by using the LuGre friction model.
Dynamic equations considering mixed clearances are derived.

(2) Influences of the different friction models on dynamic responses with mixed clearances are studied, such as the modified Coulomb friction model and the LuGre model. When the LuGre model is applied, vibration of dynamic responses is more obvious and the value of dynamic responses is bigger than that of the modified Coulomb friction model.

(3) Influences of different clearance sizes on dynamic responses with mixed clearances are investigated. With the increase in clearance sizes, peak, and vibration frequencies of dynamic responses, and slider trajectory inside the guide becomes more chaotic.

(4) Effects of different driving velocities on dynamic responses with mixed clearances are studied. With the increase in driving speeds, peak of contact force at revolute clearance pairs, contact force, and acceleration of the slider are increased, and the shaft center trajectories at revolute clearance pairs and slider trajectory become more and more chaotic.

(5) Virtual prototype model containing mixed clearances is modeled through ADAMS. The numerical calculation result is verified through the virtual simulation result.

\section{Data Availability}

The data used to support the findings of this study are included within the article.

\section{Conflicts of Interest}

The authors declare that they have no conflicts of interest.

\section{Acknowledgments}

This paper was supported by the Natural Science Foundation of Shandong Province (Grant no. ZR2017MEE066).

\section{References}

[1] X. Chen, W. Gao, S. Jiang et al., "Static and dynamic analysis of a novel single-DOF six bar mechanical press mechanism," Journal of Shandong University of Science and Technology, vol. 36, no. 5, pp. 80-90, 2017.

[2] F. X. Liu, C. Y. Wu, and L. Sun, "Analysis and test of influence of revolute joint clearance on performance of crank-rocker style transplanting mechanism," Transactions of the Chinese Society of Agricultural Engineering, vol. 32, no. 15, pp. 9-17, 2016.

[3] Y. Yang, Y. Tian, Y. Peng, and H. Pu, "A novel 2-DOF planar translational mechanism composed by scissor-like elements," Mechanical Sciences, vol. 8, no. 1, pp. 179-193, 2017.

[4] E. Zheng, R. Zhu, S. Zhu et al., "A study on dynamics of flexible multi-link mechanism including joints with clearance and lubrication for ultra-precision presses," Nonlinear Dynamics, vol. 83, no. 1-2, pp. 137-159, 2016.

[5] Q. Tian, P. Flores, and H. M. Lankarani, "A comprehensive survey of the analytical, numerical and experimental 
methodologies for dynamics of multibody mechanical systems with clearance or imperfect joints," Mechanism \& Machine Theory, vol. 122, 2018.

[6] Z. Zhan, X. Zhang, Z. Jian, and H. Zhang, "Error modelling and motion reliability analysis of a planar parallel manipulator with multiple uncertainties," Mechanism and Machine Theory, vol. 124, pp. 55-72, 2018.

[7] F. Meng, S. Wu, F. Zhang, and L. Liang, "Numerical modeling and experimental verification for high-speed and heavy-load planar mechanism with multiple clearances," Mathematical Problems in Engineering, vol. 2015, no. 3, 11 pages, 2015.

[8] F. Zhuang and Q. Wang, "Modeling and simulation of the nonsmooth planar rigid multibody systems with frictional translational joints," Multibody System Dynamics, vol. 29, no. 4, pp. 403-423, 2013.

[9] S. Erkaya, S. Doğan, and Şı Ulus, "Effects of joint clearance on the dynamics of a partly compliant mechanism: numerical and experimental studies," Mechanism and Machine Theory, vol. 88, pp. 125-140, 2015.

[10] G. Wang, Z. Qi, and J. Wang, "A differential approach for modeling revolute clearance joints in planar rigid multibody systems," Multibody System Dynamics, vol. 39, no. 4, pp. 311-335, 2017.

[11] X. Zhang, X. Zhang, and Z. Chen, "Dynamic analysis of a 3RRR parallel mechanism with multiple clearance joints," Mechanism and Machine Theory, vol. 78, no. 78, pp. 105-115, 2014.

[12] S. M. Varedi, H. M. Daniali, and M. Dardel, "Dynamic synthesis of a planar slider-crank mechanism with clearances," Nonlinear Dynamics, vol. 79, no. 2, pp. 1587-1600, 2015.

[13] Y. Chen, Y. Sun, and C. Chen, "Dynamic analysis of a planar slider-crank mechanism with clearance for a high speed and heavy load press system," Mechanism and Machine Theory, vol. 98, pp. 81-100, 2016.

[14] K. Chen, G. Zhang, R. Wu et al., "Dynamic analysis of a planar hydraulic rock-breaker mechanism with multiple clearance joints," Shock and Vibration, vol. 2019, Article ID 4718456, 17 pages, 2019.

[15] X. Li-Xin and L. Yong-Gang, "Investigation of joint clearance effects on the dynamic performance of a planar 2-DOF pickand-place parallel manipulator," Robotics and Computer-Integrated Manufacturing, vol. 30, no. 1, pp. 62-73, 2014.

[16] Y. Hou, G. Jing, Y. Wang et al., "Dynamic response and stability analysis of a parallel mechanism with clearance in revolute joint," Mechanism and Machine Science, Springer, Singapore, 2017.

[17] Y. Li, G. Chen, D. Sun, Y. Gao, and K. Wang, "Dynamic analysis and optimization design of a planar slider-crank mechanism with flexible components and two clearance joints," Mechanism and Machine Theory, vol. 99, pp. 37-57, 2016.

[18] S. Erkaya and S. Doğan, "A comparative analysis of joint clearance effects on articulated and partly compliant mechanisms," Nonlinear Dynamics, vol. 81, no. 1-2, pp. 1-19, 2015.

[19] Z. Wang, Q. Tian, H. Hu, and P. Flores, "Nonlinear dynamics and chaotic control of a flexible multibody system with uncertain joint clearance," Nonlinear Dynamics, vol. 86, no. 3, pp. 1571-1597, 2016.

[20] S. B. Farahan, M. R. Ghazavi, and S. Rahmanian, "Bifurcation in a planar four-bar mechanism with revolute clearance joint," Nonlinear Dynamics, vol. 87, no. 2, pp. 1-19, 2016.

[21] S. Yaqubi, M. Dardel, H. M. Daniali, and M. H. Ghasemi, "Modeling and control of crank-slider mechanism with multiple clearance joints," Multibody System Dynamics, vol. 36, no. 2, pp. 143-167, 2016.

[22] P. Flores, J. Ambrósio, J. C. P. Claro, and H. M. Lankarani, "Influence of the contact-impact force model on the dynamic response of multi-body systems," Proceedings of the Institution of Mechanical Engineers, Part K: Journal of Multi-Body Dynamics, vol. 220, no. 1, pp. 21-34, 2006.

[23] O. Muvengei, J. Kihiu, and B. Ikua, "Dynamic analysis of planar multi-body systems with LuGre friction at differently located revolute clearance joints," Multibody System Dynamics, vol. 28, no. 4, pp. 369-393, 2012.

[24] S. Jiang, X. L. Chen, and Y. Deng, "Dynamic response analysis of planar multilink mechanism considering wear in clearances," Shock and Vibration, vol. 2019, Article ID 5389732, 18 pages, 2019.

[25] F. Marques, P. Flores, J. C. P. Claro et al., "A survey and comparison of several friction force models for dynamic analysis of multibody mechanical systems," Nonlinear Dynamics, vol. 86, no. 3, pp. 1-37, 2016.

[26] O. Muvengei, J. Kihiu, and B. Ikua, "Dynamic analysis of planar rigid-body mechanical systems with two-clearance revolute joints," Nonlinear Dynamics, vol. 73, no. 1-2, pp. 259-273, 2013.

[27] L. Skrinjar, J. Slavič, and M. Boltežar, "A validated model for a pin-slot clearance joint,” Nonlinear Dynamics, vol. 88, no. 1, pp. 131-143, 2017.

[28] W. Li, C. Wang, C.-L. Sheng, H. Yang, and E. Lu, "Pin-slot clearance joints in multibody systems," International Journal of Precision Engineering and Manufacturing, vol. 18, no. 12, pp. 1719-1729, 2017.

[29] P. Flores, J. Ambrósio, J. C. P. Claro et al., "Translational joints with clearance in rigid multibody systems," Journal of Computational \& Nonlinear Dynamics, vol. 3, no. 1, pp. 112-113, 2008.

[30] F.-F. Zhuang and Q. Wang, "Modeling and analysis of rigid multibody systems with driving constraints and frictional translation joints," Acta Mechanica Sinica, vol. 30, no. 3, pp. 437-446, 2014.

[31] J. Zhang and Q. Wang, "Modeling and simulation of a frictional translational joint with a flexible slider and clearance," Multibody System Dynamics, vol. 38, no. 4, pp. 1-23, 2016.

[32] P. Flores, R. Leine, and C. Glocker, "Modeling and analysis of planar rigid multibody systems with translational clearance joints based on the non-smooth dynamics approach," Multibody System Dynamics, vol. 23, no. 2, pp. 165-190, 2010.

[33] T. C. Wang, G. P. Chen, F. Ma et al., "Dynamic analysis of multibody systems with mixed clearance," Journal of Vibration and Shock, vol. 35, no. 9, pp. 178-183, 2016.

[34] Z. Zhan, X. Zhang, H. Zhang, and G. Chen, "Unified motion reliability analysis and comparison study of planar parallel manipulators with interval joint clearance variables," Mechanism and Machine Theory, vol. 138, pp. 58-75, 2019.

[35] J. S. Zhou, Study on Dynamic of Flexible Mechanism Considering Joint Wear Clearance Numerically and experimentally, Harbin Institute of Technology, Harbin, China, 2016.

[36] H. M. Lankarani and P. E. Nikravesh, "A contact force model with hysteresis damping for impact analysis of multibody systems," Journal of Mechanical Design, vol. 112, no. 3, pp. 369-376, 1990.

[37] J. A. C. Ambrósio, "Impact of rigid and flexible multibody systems: deformation description and contact models," Virtual Nonlinear Multibody Systems, Springer, Netherlands, pp. 57-81, 2003. 
[38] H. Tan, Y. Hu, and L. Li, "Effect of friction on the dynamic analysis of slider-crank mechanism with clearance joint," International Journal of Non-linear Mechanics, vol. 115, pp. 20-40, 2019.

[39] M. Greco, H. B. Coda, and W. S. Venturini, "An alternative contact/impact identification algorithm for $2 \mathrm{~d}$ structural problems," Computational Mechanics, vol. 34, no. 5, pp. 410-422, 2004.

[40] S. M. Varedi-Koulaei, H. M. Daniali, M. Farajtabar, B. Fathi, and M. Shafiee-Ashtiani, "Reducing the undesirable effects of joints clearance on the behavior of the planar 3-RRR parallel manipulators," Nonlinear Dynamics, vol. 86, no. 2, pp. 1007-1022, 2016.

[41] A. A. Olyaei and M. R. Ghazavi, "Stabilizing slider-crank mechanism with clearance joints," Mechanism \& Machine Theory, vol. 53, no. 7, pp. 17-29, 2012.

[42] H. M. Lankarani and P. E. Nikravesh, "Continuous contact force models for impact analysis in multibody systems," Nonlinear Dynamics, vol. 5, no. 2, pp. 193-207, 1994.

[43] X. Chen, S. Jiang, Y. Deng et al., "Dynamics analysis of 2-DOF complex planar mechanical system with joint clearance and flexible links," Nonlinear Dynamics, vol. 93, no. 3, pp. 1009-1034, 2018.

[44] Y. Wang, Dynamics Simulation and Chaotic Phenomena Research on Two Types of Decoupled Parallel Mechanism with clearance, Yanshan University, Qinhuangdao, China, 2016.

[45] H. Zhang, X. Zhang, X. Zhang, and J. Mo, "Dynamic analysis of a 3-PRR parallel mechanism by considering joint clearances," Nonlinear Dynamics, vol. 90, no. 1, pp. 405-423, 2017.

[46] Z. Wang, Q. Tian, and H. Hu, "Dynamics of flexible multibody systems with hybrid uncertain parameters," Mechanism and Machine Theory, vol. 121, pp. 128-147, 2018.

[47] J. Baumgarte, "Stabilization of constraints and integrals of motion in dynamical systems," Computer Methods in Applied Mechanics and Engineering, vol. 1, no. 1, pp. 1-16, 1972.

[48] S. J. Zhang, Research on Dynamic Characteristics of Lunar Rover Developable Panel Mechanism with Joint clearance, Yanshan University, Qinhuangdao, China, 2016. 